Cahiers $d u$ MONDE RUSSE

\section{Cahiers du monde russe}

Russie - Empire russe - Union soviétique et États indépendants

$52 / 1 \mid 2011$

Varia

\title{
Le parti musulman Difai : Enjeux locaux, nationaux, impériaux et représentations dans le sud du Caucase (début du $\mathrm{Xx}^{\mathrm{e}}$ siècle)
}

The Muslim Difai [Defence] party: Local, national and imperial issues and representations in the Southern Caucasus (early 20th century)

\section{Édith Ybert-Chabrier}

\section{(2) OpenEdition}

Journals

Édition électronique

URL : https://journals.openedition.org/monderusse/9322

DOI : 10.4000/monderusse.9322

ISSN : 1777-5388

Éditeur

Éditions de l'EHESS

Édition imprimée

Date de publication : 5 mars 2011

Pagination : 75-113

ISBN : $978-2-7132-2351-8$

ISSN : $1252-6576$

Référence électronique

Édith Ybert-Chabrier, "Le parti musulman Difai : Enjeux locaux, nationaux, impériaux et

représentations dans le sud du Caucase (début du xx $\mathrm{e}^{\mathrm{e}}$ siècle) », Cahiers du monde russe [En ligne],

52/1 | 2011, mis en ligne le 28 mars 2014, consulté le 03 septembre 2022. URL : http://

journals.openedition.org/monderusse/9322 ; DOI : https://doi.org/10.4000/monderusse. 9322

Ce document a été généré automatiquement le 3 septembre 2022.

Tous droits réservés 


\title{
Le parti musulman Difai : Enjeux locaux, nationaux, impériaux et représentations dans le sud du Caucase (début du $\mathrm{Xx}^{\mathrm{e}}$ siècle)
}

\author{
The Muslim Difai [Defence] party: Local, national and imperial issues and \\ representations in the Southern Caucasus (early 20th century)
}

Édith Ybert-Chabrier

1 L'historiographie des partis politiques de l'Empire russe, de la Russie intérieure et des marches, s'est profondément renouvelée depuis la perestroïka et la dissolution de l'URSS. L'historienne azerbaïdjanaise Irada Bagirova a participé à ce renouvellement en publiant la première synthèse consacrée aux organisations politiques de l'Azerbaïdjan au début du $\mathrm{Xx}^{\mathrm{e}}$ siècle $^{1}$. Présentant l'ensemble des partis de la mouvance socialiste, ceux de la tendance libérale et les partis nationaux (arméniens, azerbaïdjanais, russes, sionistes), son livre repose sur l'exploitation de très nombreux documents d'archives. Il présente le parti Difai [Défense] comme la seule organisation politique des musulmans d'Azerbaïdjan jouissant d'une certaine assise populaire, sa mouvance étant beaucoup plus grande que celle du parti social-démocrate musulman Gummet [Effort], présent au même moment sur la scène politique et mis au premier plan par l'historiographie soviétique. Une recherche sur le parti Difai apparaissait dès lors intéressante pour tenter de comprendre comment s'est constituée la vie politique et nationale de communautés rurales ou urbaines qui, avant la révolution russe de 1905-1907, semblaient vivre en dehors de toutes préoccupations politiques.

2 Les sources relatives à ce parti sont presque exclusivement policières. Elles constituent un ensemble documentaire riche et incitent à replacer l'activité du Difai non seulement sur la scène politique russe et transcaucasienne mais dans la vie publique. Pour ce faire, il est utile de mettre à profit les apports des approches relevant de l'anthropologie historique, de l'étude des politiques publiques, de la sociohistoire et de la sociologie 
politique ${ }^{2}$. En effet, les leaders du parti appartiennent tous à différentes sociétés caritatives ou d'encouragement à l'éducation et occupent des fonctions publiques dans la société multinationale du Sud-Caucase. Ils tentent de faire évoluer des communautés qu'ils considèrent eux-mêmes comme arriérées et menacées dans leur existence même. Ces faits rendent particulièrement pertinente une approche de sociologie politique de l'action publique, appliquée à un groupe actif entre 1906 et 1908 et dans un contexte géopolitique certes bien éloigné de ceux des sociétés américaines ou européennes pour lesquelles les concepts de cette sociologie ont été élaborés depuis les années 1930. D'éminents historiens russes ont d'ailleurs convoqué l'histoire des mentalités, la psychologie et l'anthropologie pour étudier les révolutions russes du début du $\mathrm{XX}^{\mathrm{e}}$ siècle ${ }^{3}$ qu'ils intègrent dans la longue durée et V.P. Buldakov plaide pour le recours à l'anthropologie sociale et juridique ${ }^{4}$. C'est donc une nouvelle lecture de rapports policiers, dont la synthèse factuelle a déjà été faite par Irada Bagirova puis par Eldar Azizov $^{5}$, complétée par des informations sur les acteurs et sur le théatre de leur action, qui est proposée ici.

3 Il s'agira d'analyser les textes des manifestes et des programmes, l'action du parti sur le terrain et de les replacer dans le contexte du violent conflit interethnique entré dans l'histoire sous la dénomination de "guerre arméno-tatare» (1905-1906) et des interactions complexes et évolutives entre pouvoir impérial russe, musulmans et Arméniens, eux-mêmes en relation avec leurs coreligionnaires de l'Empire ottoman ou de l'Iran tout proches. Cette contextualisation de l'action politique et de la violence, du recours au terrorisme en particulier, permettra de repérer des caractéristiques et modes d'action communs aux différentes organisations politiques de Transcaucasie et de mettre en exergue les singularités de la vie sociale et politique des musulmans du sud du Caucase. L'accent sera mis sur les enjeux, sur leurs composantes locales, nationales - il faudra préciser celles-ci en évitant une vision téléologique de la fin de l'Empire russe et de la création des républiques transcaucasiennes -, et impériales. Le parti Difai est principalement implanté dans le gouvernement d'Elisavetpol' (Gandja), dont l'histoire a été beaucoup moins étudiée que celle de Baku et de sa région, et c'est de ce gouvernement que provient la majorité des enquêtes de terrain sur le parti. Son action s'inscrit dans un cadre «national» qui peut-être caractérisé comme turc de Transcaucasie, azerbaïdjanais, musulman du Caucase, ou encore musulman de Russie. Enfin, la composante impériale, en dehors d'une dimension musulmane panrusse (" panmusulmane »), va bien au-delà de l'administration, de la police et de leur action au Caucase. En effet, les événements de ce territoire, grèves de Baku ou massacres arménotatars, sont immédiatement présentés et commentés par les journaux de SaintPétersbourg et de Moscou. Polémiques dans la presse ou débats à la Douma d'État reposent sur des représentations antagonistes qui montrent comment préjugés nationaux et engagements politiques fondent les perceptions des différents protagonistes, lesquelles influencent durablement l'historiographie.

\section{Les sources}

Les sources, quelles qu'elles soient, - rapports des chefs de districts (uezdnye načal'niki) de la police du gouvernement d'Elisavetpol' qui décrivent l'activité des militants sur le terrain, synthèses établies à la chancellerie du gouvernement d'Elisavetpol', exposé présenté lors d'un congrès qui réunit, en mai 1908 à Tiflis, les directeurs des différentes 
organisations de gendarmerie et de police politique actifs au Caucase, matériel élaboré pour la formation des corps de gendarmerie et de police politique de l'Empire apportent des renseignements souvent complémentaires ${ }^{6}$.

Transcaucasie : divisions administratives. Début du $x x^{\mathrm{e}}$ siècle. Le gouvernement d'Elisavetpol' et ses districts. D'après Artur Cuciev, Atlas ethnopolitičeskoj istorii Kavkaza, 1774-2004 [Atlas d'histoire ethnopolitique du Caucase, 1774-2004], M. : Evropa, 2006

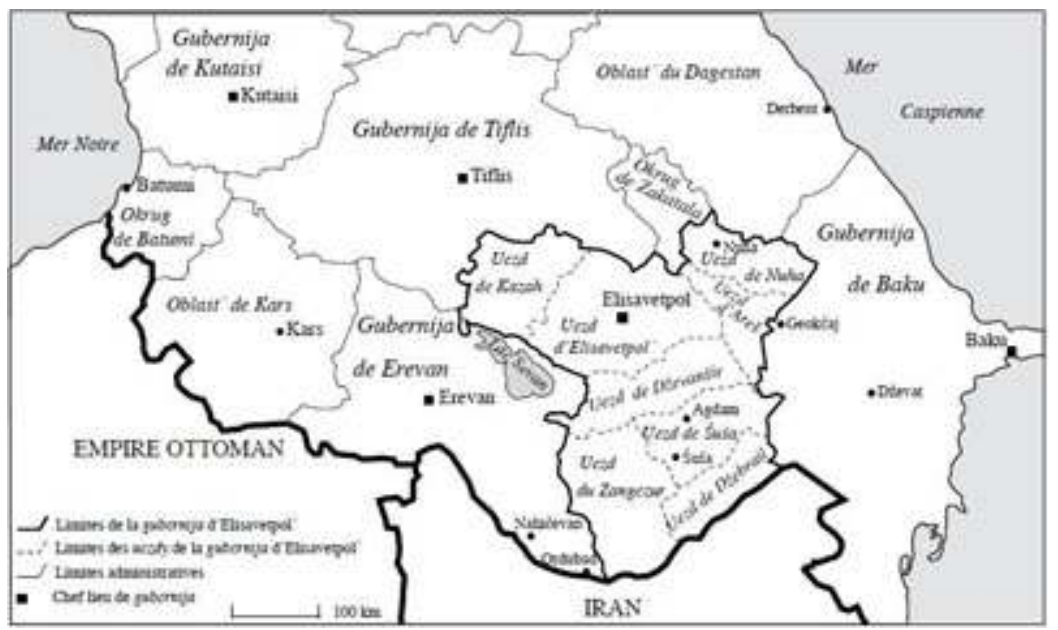

Le parti Difai se manifeste par des appels rédigés en russe et en azéri et diffusés à Baku, à Elisavetpol' et à Tiflis en octobre 19067. Une directive du 30 mai 1907 diligente des enquêtes secrètes sur ses membres et sur son « activité criminelle » dans les districts du gouvernement d'Elisavetpol' où le parti vient de s'implanter. Cette directive et les rapports émanant de six districts du gouvernement ont été publiés à Baku dès 1920 par Kričinskij. En effet le Tatar de Pologne, Lev (alias Arslan) Konstantinovič Kričinski (1887-1939), avocat de son état, a obtenu, en octobre 1919, la création d'une commission chargée de rassembler des documents sur la politique russe à l'égard des musulmans en Transcaucasie $^{8}$. Cette commission a fait paraitre en 1920 à Baku un premier recueil comportant des rapports témoignant de la vie politico-sociale de petites villes ou de villages du gouvernement d'Elisavetpol' en 1907-1908. Une partie de ces documents se trouve également conservée dans divers fonds d'archives: à Baku, aux Archives historiques (GIA AR) et aux Archives nationales des partis politiques et des mouvements sociaux de la république d'Azerbaïdjan (GAPPOD AR), à Tbilissi, aux Archives historiques centrales de Géorgie (CGIA GR), ou encore à Moscou, aux Archives d'État de la Fédération de Russie (GARF), des copies étant envoyées aux différents départements de police s'informant les uns les autres. Ces fonds d'archives renferment de surcroît de nombreux rapports d'enquêtes locales sur les activités du Difai et d'autres partis de Transcaucasie dont quelques-uns seront évoqués dans cet article ${ }^{10}$. C'est à partir des textes publiés par Kričinskij qu'Ahmedov décrit l'action du parti dans le livre qu'il rédige en $1926^{11}$. Il utilise aussi un rapport de l'Ohrana qui apporte des compléments intéressants sur les activités terroristes du Difai ${ }^{12}$. Ahmed Ahmedov (1900-1928), jeune militant bolchevik déçu dans ses aspirations nationalistes, s'inscrit en 1925 au parti Musavat qui mène encore quelques activités illégales. Il est arrêté en 1927 et exécuté l'année suivante ${ }^{13}$.

Conservés au GARF, des documents de synthèse apportent un éclairage différent, tout en reproduisant un discours qui s'est élaboré sur le terrain. Parmi eux, l'exposé du capitaine Ergardt, adjoint au directeur de l'Ohrana régionale, lors du congrès réunissant à Tiflis du 25 au 31 mai 1908 des cadres de la sécurité et de la gendarmerie. Il porte sur le Difai et 
cinq autres partis révolutionnaires musulmans de moindre importance et est reproduit avec, en annexes, le programme du parti Difai et celui de son antenne au Karabah, le Karabahskij medžlis edinenija (Assemblée du Karabah pour l'union) ${ }^{14}$. Lors de ce congrès, le capitaine Lenčevskij intervient sur le parti révolutionnaire arménien Dašnakcutjun (Dachnaktsoutioun) et sa communication, augmentée des comptes rendus de diverses réunions de ce parti, figure dans le même dossier ${ }^{15}$. Enfin, un document intitulé « Revue des mouvements révolutionnaires caucasiens ", élaboré en 1909, consacre dix-sept pages aux partis révolutionnaires arméniens, puis décrit en trois pages les partis Dfaj et Mudafie $^{16}$, proche du précédent mais au rayon d'action encore plus local, et mentionne dans sa dernière page les partis musulmans de la mouvance sociale-démocrate ${ }^{17}$. Cette répartition, adoptée dans des documents destinés à la formation des gendarmes et des agents de l'Ohrana, témoigne des préoccupations des forces de maintien de l'ordre, estimant les mouvements musulmans encore faibles, du moins dans leur phase initiale d'implantation.

7 Ces rapports policiers russes constituent la principale source d'information. Ils peuvent être confrontés à des documents des archives ottomanes ${ }^{18}$ et aux témoignages ou récits rédigés en turc par des militants caucasiens. Parmi eux figurent Mirza Bala, qui a publié dans diverses revues de Turquie, de Varsovie ou de Munich et a consacré un livre au mouvement national d'Azerbaïdjan ${ }^{19}$, et Hüseyin Baykara, établi à Istanbul ${ }^{20}$. Dans les quelques pages qu'ils consacrent au parti Difai, les chercheurs américains Audrey Altstadt $^{21}$ et Tadeusz Swietochowski ${ }^{22}$ font référence aux Mémoires parus à Istanbul (1964) de Naki Keykurun (pseudonyme de Nagi Šejhzamanov [1883-1967] qui fut ministre de la Sécurité nationale de la république démocratique d'Azerbaïdjan) ${ }^{23}$. Ce récit héroïsé, dont une traduction anglaise est diffusée sur Internet ${ }^{24}$, sera utilisé marginalement. Un nouvel intérêt pour ce parti s'est traduit récemment par l'édition à Baku des mémoires de Naği şeyxzamanl ${ }^{25}$ et d'une monographie d'Eldar Azizov, chef du pouvoir exécutif de Gandja ${ }^{26}$.

\section{Enjeux locaux et visées « panmusulmanes »}

8 Tant par son implantation que par son programme, le Difai est un parti local. Il se nomme pourtant "Comité panmusulman caucasien "Défense" ${ }^{27}$. Il s'est organisé dans les gouvernements de Baku et d'Elisavetpol' ${ }^{28}$ d'où il agit dans celui d'Erevan ${ }^{29}$; des sections ont aussi été créées en 1907 dans l'oblast' de Kars ${ }^{30}$; Il agit également à Tiflis, au Daghestan et dans le gouvernement du Terek, à Vladikavkaz ${ }^{31}$. Son comité central se trouve à Baku, mais il est principalement implanté dans le gouvernement d'Elisavetpol', dans cinq de ses huit districts.

Constitué sur le territoire des anciens sultanats de Šamšadil et de Kazah du royaume géorgien de Kartli-Kakhétie, annexé par les Russes en 1801, et des anciens khanats de Šeki, Gandja et du Karabah cédés par l'Iran en 1813, le gouvernement d'Elisavetpol' est créé lors de la réorganisation administrative de la Transcaucasie (décembre 1867). La nouvelle entité rassemble des territoires appartenant précédemment aux gouvernements de Tiflis (district d'Elisavetpol'), de Baku (districts de Nuha [Šeki] et de Šuša) et d'Erevan (une partie du district d'Ordubad qui est alors supprimé). Deux nouveaux districts (Kazah, Zangezur) y sont immédiatement créés, auxquels s'ajoutent trois autres (Areš, Džebrail [Karjagin] et Dževanšir) formés en $1873^{32}$, si bien que le gouvernement est divisé en huit districts. Sa population est principalement constituée de $60,80 \%$ de Turcophones, 
que les autorités russes nomment "Tatars ", et de 33,26\% d'Arméniens ${ }^{33}$. Les Russes n'y représentent que $2,4 \%$ des habitants, présents dans les villes, surtout comme fonctionnaires civils ou militaires, mais pas totalement absents des campagnes du fait de la politique de colonisation agricole ${ }^{34}$. Pour Sagateljan ${ }^{35}$, député arménien des gouvernements de Baku, d'Elisavetpol' et d'Erevan à la III Douma, «l'Arménie russe est constituée des gouvernements d'Erevan et d'Elisavetpol', ainsi que d'une partie du gouvernement de Tiflis et de la région de Kars »; sur son territoire vivent 1200000 Arméniens, y représentant un peu plus d'un tiers de la population totale ${ }^{36}$. Une partie des régions qui constituaient le gouvernement d'Elisavetpol' va être l'objet de contestations territoriales entre les républiques indépendantes d'Arménie et d'Azerbaïdjan proclamées en 1918. Par suite de la soviétisation et des arbitrages intervenus de 1920 à 1923, elles ont été organisées de la sorte : la majeure partie des districts de Zangezur et de Kazah a été attribuée en 1921 à la république soviétique d'Arménie, une partie des districts de Šuša, Dževanšir et Džebrail ont constitué la région autonome du Haut-Karabah, instaurée en 1923 au sein de la république soviétique d'Azerbaïdjan, à qui a été attribué également le reste du gouvernement de Gandja ${ }^{37}$.

10 À partir de deux pôles principaux, les villes d'Elisavetpol' (Gandja) [33 625 hab. dont $52,5 \%$ de musulmans et près de $36 \%$ d'Arméniens] et de Šuša ( 25881 hab. dont près de $42 \%$ de musulmans et 55,5\% d'Arméniens $\left.{ }^{38}\right)$, le parti Difai a essaimé dans les districts dont ces villes sont les centres et dans ceux de Dževanšir, Zangezur, et Džebrail, ces deux derniers étant limitrophes de la Perse. Dans ces cinq districts, la population musulmane est majoritairement chiite (à plus de 85 \% pour ceux de Šuša et de Dževanšir) ${ }^{39}$. Dans le district de Kazah, c'est un parti de la même mouvance mais cependant distinct, le parti Mudafie, qui est le plus actif ${ }^{40}$. Le Difai a même atteint des villages de quelques dizaines de feux, comme Barda (district de Dževanšir) ou Hodžagan (district de Zangezur) ${ }^{41}$. Comme le remarquent plusieurs rapports, dont celui du gouverneur d'Elisavetpol', c'est parce que Šuša et son district ont le plus souffert à l'époque des massacres arméno-tatars que le parti Difai a pu y mener son action ${ }^{42}$. Son fondateur, Ahmed Agaev (Ağaoğlu), natif de Šuša, y a résidé à nouveau en 1896, y enseignant le français ${ }^{43}$. Il y rassemble en août 1906 « les Tatars influents et honorables». Il parcourt ensuite tout le Karabah pour y organiser les comités du parti ${ }^{44}$. Keykurun ${ }^{45}$, Hüseyin Baykara ${ }^{46}$ font tous deux remonter les débuts du parti à 1905, le premier à Genje (Gandja), le second à Baku, avant l'année 1906 retenue par les enquêtes policières.

11 T outes les sources concordent pour lier la création du parti aux heurts arméno-tatars de 1905-1906 et le programme du parti est tout à fait explicite sur ce point. Le rapport du capitaine Ergardt (mai 1908) dépeint ainsi le contexte :

Jusqu'au moment où les musulmans du Caucase se flattaient de la fausse conviction que, dans leurs heurts sanglants avec les Arméniens, ils auraient représenté l'élément loyal opposé aux masses arméniennes favorables à la révolution, et le temps que l'administration du Caucase a soutenu cette conviction dans cette nationalité, celle-ci a effectivement été au fond loyale. Mais, quand les chefs du mouvement [Difai] se persuadèrent que ni le gouvernement central ni ses représentants au Caucase n'étaient plus enclins à soutenir une telle aberration, [...] ils appelèrent la population musulmane à agir contre l'administration, et même par la voie de la terreur. ${ }^{47}$

12 En des termes beaucoup moins feutrés, l'appel diffusé en octobre 1906 par le parti Difai fait aussi référence à un changement intervenu dans la politique russe au Caucase :

Les hommes du gouvernement, particulièrement dans ces sinistres jours de la viceroyauté de Voroncov-Daškov, courbant lâchement l'échine devant les bombes et 
les balles de l'organisation arménienne «Dašnakcutjun" sont devenus les instruments dociles de cette organisation au Caucase. ${ }^{48}$ effet, la confiscation des biens du clergé arménien en 1903 avait provoqué la mobilisation de toutes les couches de la population contre le pouvoir tsariste et explique en grande partie leur participation massive à la révolution russe de $1905^{49}$. Parmi les mesures prises par le gouvernement tsariste confronté à la situation explosive de la région figurent le rétablissement, en février 1905, de la vice-royauté (institution qui avait été abolie en 1881), au profit du comte I.I. Voroncov-Daškov et la restitution de ses biens au clergé de l'Église arménienne ( $1^{\text {er }}$ août 1905).

Ce n'est pas spécifiquement cette mesure que dénoncent les fondateurs du Difai, mais la prétendue soumission du vice-roi et de ses subordonnés aux dašnaks et l'adoption de leurs plans «d'extermination ou d'expulsion des musulmans hors des limites du territoire du Caucase, dans le but de prendre leur territoire et, à la suite de cela, d'assurer au peuple arménien du Caucase une administration autonome nationale». Et ils poursuivent, dénonçant la complaisance de Voroncov-Daškov, grâce à laquelle le plan dašnak s'accomplit : le district de Zangezur, des parties des districts de Šuša, Džebrail et Dževanšir sont effectivement devenus des possessions des Arméniens, disent-ils ${ }^{50}$. Du côté des révolutionnaires arméniens, l'hostilité à la politique du vice-roi s'exprime dans des termes aussi violents. E. Aknouni dénonce « ce faux prophète qui préparait la guerre tout en prêchant la paix» et sa collusion avec les "délégués turcs et les chefs panislamistes $\aleph^{51}$. Sa politique a déchaîné bien des passions et des critiques et a été réappréciée dans des études historiques récentes ${ }^{52}$. délogées de leurs foyers, ruinées, errent dans le gouvernement d'Elisavetpol', ne trouvant ni refuge, ni défense, ni nourriture, ni abri ». Pour sauver les musulmans du Caucase de la disparition qui les menace, le parti va agir par l'éducation des masses et par la force (le recours aux armes et à la terreur) ${ }^{53}$. Le parti s'implante en effet sous couvert de sociétés de bienfaisance et de comités d'aide aux victimes de la faim. Il est le plus souvent appelé " commission », « comité », « medžlis« (assemblée) » du Karabah, ou « Karabahskij medžlis edinenija », Assemblée du Karabah pour l'union, dans les districts où il s'implante ${ }^{54}$. Ces appellations témoignent bien de l'importance des enjeux locaux, ceux du Karabah précisément. D'après les rapports de police, le programme diffusé par le parti dans la population, «pour les gens simples » différerait du programme complet qui n'est en la possession ni du chef de district de Dževanšir ni du gouverneur d'Elisavetpol ${ }^{55}$. Mirza Bala et Hüseyn Baykara ${ }^{56}$ se réfèrent explicitement au manifeste dont des extraits, destinés aux masses, sont parus à Baku dans le journal Iršad [Le Guide] du 13 octobre $1906^{57}$. En revanche, ni le programme d'action arrêté lors du " congrès des représentants de la population musulmane de Transcaucasie, du Caucase du Nord et de Crimée » réuni à Elisavetpol', en mars 1907, ni le programme en 52 (ou 53) points, élaboré en octobre 1907, par l'Assemblée du Karabah pour l'union ${ }^{58}$ ne semblent connus ni des responsables de la police locale ni des militants ou historiens azerbaïdjanais de l'émigration.

Le programme d'action de mars 1907 comporte cinq points :

1. Organiser dans un futur proche un congrès semblable en Crimée, avec pour but l'organisation d'un congrès général musulman, à l'exemple du Dašnakcutjun arménien et, ayant recouru à la terreur, obtenir par cette voie des concessions du gouvernement, comme l'a fait l'organisation susnommée ; 
2. Établir ce printemps (1907) au Karabah (district de Šuša) « Dfaj » pour contrebalancer les « humb $~^{59}$ arméniens et choisir les chefs ;

3. Terroriser avant tout les représentants de l'administration et des tribunaux;

4. À l'aide des capitalistes musulmans de Baku acheter aux Arméniens toutes les terres de Agdam à la station de Hodžaly ${ }^{60}$, pour l'établissement uniquement de musulmans ;

5. Obliger les ressortissants de Šuša à vivre obligatoirement dans leur ville et, en général, faire du Karabah une province musulmane $»^{61}$.

L'objectif d'homogénéisation de territoires par chacune des deux nationalités rivales s'affirme dès cette époque. Il est évoqué lors de la réunion régionale du Dašnakcutjun (13-14 novembre 1905) où plusieurs délégués affirment la nécessité pour les Arméniens d'acquérir des terres auprès des Tatars et de former une "masse compacte ${ }^{62}$. Ce même objectif inspire directement les points 4 et 5 du programme de mars 1907 du Difai. Selon l'analyse de Voroncov-Daškov, le Dašnakcutjun « aspire à former des territoires plus ou moins considérables avec une population compacte arménienne, dans le but de préparer un terrain meilleur pour la création future de l'autonomie de l'Arménie ${ }^{63}$. L'objectif de « nettoyage » (otčistka) d'un territoire national des éléments étrangers n'a pas été atteint par les protagonistes de la guerre arméno-tatare de 1905-1906, selon V.N. Hudadov : ils ne sont parvenus à éliminer ni la dizaine de villages arméniens plongés dans la «mer turque » des districts de Areš et de Nuha, ni les villages tatars disséminés dans la « masse arménienne » du Zangezur et de la partie montagneuse du district de Šuša. Mais, dit-il, ces visées inspirent dès lors les leaders des mouvements nationaux, tant turcs qu'arméniens $^{64}$. Le document de synthèse analytique sur les mouvements révolutionnaires caucasiens de 1909 voit comme résultat de l'action du parti dašnak la délimitation (razmeževanie) de territoires arméniens et tatars ${ }^{65}$.

Pour la défense du territoire du Karabah, le parti fait appel à l'ensemble des musulmans de Transcaucasie, du Caucase du Nord et de Crimée. En se proclamant «Comité panmusulman (ou Union panmusulmane) du Caucase Difai », le parti met en exergue son caractère islamique, qu'il ne faut pas confondre avec une allégeance au panislamisme, mouvement d'union des musulmans sous l'égide du calife ottoman que les autorités tsaristes considèrent contraire aux intérêts de l'État russe et qu'elles redoutent et combattent. Ce caractère musulman est interprété de différentes façons selon les auteurs. Bagirova ou Keykurun ne le mettent pas en avant et remplacent volontiers l'appellation « musulman » par " azerbaïdjanais ». Rappelons que cet ethnonyme est rarement usité pour désigner ceux que les Russes nomment «Tatars » et qui, eux-mêmes, ne se désignent pas encore comme "Turcs» comme ils le feront systématiquement dans les années 1920 ou comme "Azerbaïdjanais", terme d'usage exclusif depuis les années $1930^{66}$. Mais, s'agit-il de termes équivalents? Les historiens sont partagés. Mirza Bala insiste sur le "nationalisme islamique» du Difai et sur ce qui le distingue du «nationalisme turc» du parti Musavat [Égalité], créé clandestinement en $1911^{67}$. Hudadov fait d'une vision du monde exclusivement religieuse un trait dominant des sociétés musulmanes de Transcaucasie. Pour les Turcs de cette région, précise-t-il, la communauté de religion avec la Perse reléguait à l'arrière-plan la communauté nationale avec les Turcs ottomans ${ }^{68}$. Mais sur cette toile de fond qui demeure encore, s'élabore depuis les années 1870 , et à un rythme rapide après 1905, l'identité nationale azerbaïdjanaise ${ }^{69}$, passant d'un ancrage iranien chiite à un nationalisme turc et dépassant ainsi le clivage traditionnel entre sunnites et chiites. L'activité du Difai se déploie 
précisément durant ces années charnières et elle se révèle aussi un ferment accélérant le développement de la conscience nationale.

Ces années sont également celles de la création de l'Union des musulmans russes (Sojuz Rossijskih musul'man, Rusya Müsülmanlarinın Ittifakl) en août 1905, organisation dont l'existence demeure semi-légale jusqu'à la fin du régime tsariste. Ali-Merdan Toptchibachy ${ }^{70}$, député de la ville de Baku à la I ${ }^{\text {re }}$ Douma, est élu président du Comité central de l'Union des musulmans lors de son III congrès (16-21 août 1906). Cette organisation commune à tous les musulmans de Russie s'émeut des heurts qui perdurent entre Arméniens et musulmans et de la situation préoccupante de Šuša, de son district et de celui du Zangezur et adopte une résolution à ce sujet ${ }^{71}$. Ainsi, le Difai, avec son ancrage local et ses visées panmusulmanes, reflète bien deux tendances qui coexistent chez les musulmans de Russie, la défense d'une " autonomie culturelle nationale » et la conscience de former des sociétés ethnoterritoriales, tendances présentes dans l'Union des musulmans dès ses débuts ${ }^{72}$ et encore représentées dans les débats de 1917 sur le type d'autonomie et de fédéralisme à mettre en place au sein du nouvel État russe ${ }^{73}$.

$\mathrm{U} n$ autre point est à relever. Le manifeste du parti exprime la menace de disparition que ressentent les musulmans du Caucase. Ce sentiment qui préoccupe de nombreux penseurs musulmans du début du $\mathrm{xx}^{\mathrm{e}}$ siècle peut paraitre outré ou déplacé à ceux qui connaissent la situation géopolitique mondiale du début du xxI ${ }^{e}$ siècle. Mais, face à l'expansion du colonialisme et à la faiblesse de l'Empire ottoman, le spectre de l'annihilation du monde musulman hante publicistes et analystes de l'époque. C'est également dans la perspective d'une " déislamisation ", d'un islam "qui disparaît politiquement " et " ne subsistera bientôt qu'à l'état d'une civilisation installée au milieu des dominations occidentales » que se place le directeur de la revue française d'islamologie, A. Le Chatelier, dans un numéro spécial de $1911^{74}$.

\section{L'action sur le terrain}

21 Avec ses mille membres, le Difai se révèle le plus important des partis musulmans de Transcaucasie avant 1917. Il se réclame lui-même dans son manifeste de «mille jeunes gens, rassemblés de partout au Caucase du Nord, au Daghestan et en Transcaucasie ${ }^{75}$. Bagirova établit ce nombre, le répartissant entre les membres des comités et les propagandistes agissant à partir de sept villes du gouvernement d'Elisavetpol' et depuis Baku, au total 160 militants, et les combattants des milices du parti, dont les effectifs sont estimés à 900 hommes $^{76}$.

Les rapports de police constatent que les militants, membres du Comité central, des comités et des sous-comités locaux, appartiennent à la Société musulmane centrale de bienfaisance $^{77}$ ou à l'association Gidajat [L'Éducation morale] ${ }^{78}$ et s'introduisent en cette qualité $^{79}$ auprès des populations qu'ils veulent mobiliser. Dans les villages, ils rassemblent le peuple sous le prétexte d'enquêtes sur ses besoins économiques et là, au passage, ils expliquent les exigences de la charia, le convainquent d'arrêter le vol de bétail, le pillage, de renoncer à la coutume de la vengeance du sang, lui demandent de ne pas épargner les déviants et prônent des rapports pacifiques avec les Arméniens. Après cela, le peuple est amené à prêter serment de vivre selon la charia. Lors de ce serment général, les agents du parti observent la population du village et repèrent les plus évolués et réceptifs de ses membres, de préférence parmi les jeunes. Après de longues conversations, en tête à tête, ils leur font prêter un serment spécial. Ainsi enrôlés comme 
membres du parti, ils sont chargés de la propagande à mener prudemment et conséquemment et de la surveillance de la société des villages. Ce rituel est décrit par le gouverneur d'Elisavetpol'so et par le chef de la police du district de Dževanšir ${ }^{81}$, le capitaine de gendarmerie Džandieri ${ }^{82}$, tandis que la dénonciation hostile de Safaralibekov mentionne l'utilisation de la bienfaisance et le serment de la population ${ }^{83}$. L'action du parti passe aussi par le prélèvement de dons au profit des victimes de la faim et par le paiement d'amendes infligées à ceux qui manquent aux exigences de la charia ou aux prescriptions énoncées par le parti ${ }^{84}$, toutes sommes reversées aux sociétés de bienfaisance mentionnées ci-dessus. En décembre 1907, Džandieri constate que les responsables ruraux dans les districts et les anciens (aksakaly, littéralement «barbes blanches ») des villages penchent en faveur de l'Assemblée du Karabah pour l'union. Dans le district de Dževanšir par exemple, dans les 38 communautés paysannes ${ }^{85}$ qu'il comporte, Džandieri ne peut compter que sur huit maires (staršiny) loyaux envers le gouvernement, tous les autres postes sont aux mains du parti ${ }^{86}$. Safaralibekov évoque le bazar d'Agdam entièrement gagné à la cause du parti ${ }^{87}$.

Comment se traduit son action? D'abord par le boycott des institutions de l'État, particulièrement des tribunaux. Ce trait, relevé à plusieurs reprises à propos du Difai ${ }^{88}$, caractérise aussi le mouvement agraire de Gourie encadré par les sociaux-démocrates ${ }^{89}$ et l'action du parti dašnak ${ }^{90}$. Ainsi s'est développé à partir de 1903, dans certaines régions de Transcaucasie engagées massivement dans des actions révolutionnaires, un selfgouvernement qui gère les affaires locales à la place des fonctionnaires et des juges officiels. D'une façon semblable, en 1907, au Karabah, après deux années de troubles, les tribunaux ruraux restent inactifs et une « justice sommaire » est rendue par les comités du Difai ${ }^{91}$.

D'une façon générale, l'action du parti s'exerce de deux manières. D'une part, il intervient dans le tissu social et y met en œuvre son programme d'éducation, d'autre part, il forme des milices armées pour protéger les musulmans et mène des actions terroristes ciblées à l'encontre de représentants du pouvoir tsariste et de musulmans considérés comme des traitres envers leur communauté. Le premier volet de son action vise la moralisation et l'unité du peuple car, comme il est dit dans le manifeste d'octobre 1906, non seulement il court à sa perte sous la pression d'ennemis extérieurs, mais il s'annihile lui-même, par le brigandage et les assassinats ${ }^{92}$. Le programme en 52 (53) points élaboré, en octobre 1907, par l'Assemblée du Karabah pour l'union donne des règles précises de conduite touchant à tous les domaines (vie privée, activités sociales et économiques) et il entend combattre les entraves à l'unité du peuple (divisions religieuses, inimitiés entre membres de la communauté). Il se présente beaucoup plus comme un code moral de conduite, rigoriste et puritain, que comme un programme politique. Ce code est directement inspiré de la charia à laquelle il se réfère explicitement dans son article 13, sans exclure « la loi » (art. 25) et l'autorité traditionnelle représentée par l'assemblée des musulmans (art. 24) ou l'assemblée du village, shrod obščestva, (art. 30). Ce programme prévoit par exemple de poursuivre tous les manquements à une stricte morale des mœurs, depuis le rapt des jeunes filles jusqu'à l'adultère et l'homosexualité (art. 18, 22), réglemente la vengeance du sang (art. 24, 25), les rites de deuil (art. 38). En fait il s'intéresse de près aux domaines qui relèvent du droit coutumier et y imposent ses propres normes, au nom de la charia et de la loi. Par ailleurs, il promeut une organisation économique favorable aux musulmans en poursuivant ceux qui pratiquent des prix trop élevés ou accaparent des produits de première nécessité (art. 26, 27), en prescrivant des achats exclusivement auprès des commerçants musulmans (art. 52) et en recommandant aux plus aisés de constituer des 
sociétés par actions pour l'achat des produits agricoles (art. 36) ${ }^{93}$. Certaines prescriptions portent sur des aspects de la vie sociale qui n'entrent pas dans le cadre des rapports policiers précédemment évoqués. Ces derniers, en revanche, montrent que les consignes concernant les litiges à soumettre aux comités du parti avant toute démarche ultérieure ou les élections dans les assemblées locales ont été appliquées à la lettre. Une certaine moralisation, conformément aux prescriptions de la charia, semble effective. Džandieri, constatant la disparition des vols de bétail et la diminution des attaques de brigands, y voit la conséquence de la répression menée sous le régime de l'état d'urgence instauré dans la région, sans nier totalement le rôle du parti ${ }^{94}$. Le gouverneur d'Elisavetpol', dans son rapport d'août 1907, note l'intérêt suscité par la révolution constitutionnelle iranienne même dans des villages reculés, le dépassement du clivage sunnites/chiites dans le peuple sans éducation et la foi dans l'école dont l'utilité est désormais reconnue. Il constate qu'en un ou deux ans les "Tatars locaux » ont beaucoup progressé dans la participation à la vie sociale ${ }^{95}$. Pour lui, il est clair que « le parti se trouve aux mains de gens intelligents, prudents, conséquents, honnêtes et sincères $»^{96}$.

Le parti accomplit un certain nombre d'attentats. Toutes les notices consacrées au Difai, les récits, les rapports mentionnent l'assassinat du général Gološčapov ${ }^{97}$, gouverneur de Šuša au moment des heurts arméno-tatars. Lors de son attentat, perpétré le 8 novembre 1906 à Tiflis, le parti émet la déclaration suivante : « Le général Gološčapov est condamné à mort par le parti Dfaj pour sa collaboration aux crimes du Karabah $»^{98}$. Une certaine fierté de la détermination et de l'efficacité du parti dans cette affaire pointe dans le récit d'Hüseyin Baykara: la mission a été confiée à un certain «Hüsü» de Šuša; elle est accomplie en une semaine et, avec l'aide du Difai, l'exécuteur passe en Iran ${ }^{99}$. Cette version héroïse la réalité. Il ressort d'une déposition obtenue d'un détenu de la prison de Šuša en 1908-1909 que l'exécution a eu lieu après une minutieuse préparation et une traque de plusieurs mois et que l'exécuteur, Gjusi Ali, est revenu dans son village toucher la somme de 1500 roubles qui lui avait été promise ${ }^{100}$. L'un des collaborateurs du général Gološčapov au moment des événements de Šuša, le conseiller Kleščinskij, est exécuté à Elisavetpol' le 25 avril 1907, attentat revendiqué dans des déclarations du parti, tout comme celui de décembre 1906 du lieutenant-colonel Enkel, qui dirigeait le département de police du district de Nahičevan au moment des massacres arméno-tatars ${ }^{101}$. En dehors de ces personnalités en vue, sont visés des agents de police, d'origines nationales diverses, un certain gendarme Žukov ${ }^{102}$, un chef de police Israfilbekov ${ }^{103}$ et des musulmans accusés d'espionnage, de délation, de participation à une compagnie commerciale à capitaux arméniens ou de pratiques usurières ${ }^{104}$. Parmi eux, un certain mollah Hedi de Gandja est liquidé pour sa collaboration avec la police ${ }^{105}$.

Il n'est pas évident d'établir une frontière stricte entre des actes terroristes politiques ou révolutionnaires et des délits ou crimes de droit commun. C'est principalement à des hors-la-loi en fuite qu'est confiée l'exécution rétribuée des actes terroristes, affirme Safaralibekov dans sa déposition de mars $1908^{106}$. L'existence de réseaux impliqués dans les actions terroristes s'accompagne de proférations de menaces de mort à l'encontre des traitres, de pressions pour la collecte des fonds nécessaires à leur financement et de rapports tendus ou conflictuels au sein des communautés villageoises concernées ${ }^{107}$.

Par ailleurs, le parti constitue des milices armées, dont la plus importante est celle de Šuša, « composée de 400 jeunes gens, bien armés »108. Les milices formées auprès des comités locaux rassemblent des brigands, des fugitifs échappés des bagnes et des hors-la- 
loi de tout poil, d'après le gouverneur d'Elisavetpol'109. Ces milices semblent jouer un rôle de dissuasion. Il n'y a plus de combats entre formations arméniennes et musulmanes après l'automne 1906. Est-ce dû à la lassitude des deux nationalités, qui ont pris conscience de la nocivité pour chacune d'elle des conflits qui les ont récemment opposées, comme le dit Voroncov-Daškov110110, ou à l'effet induit par la constitution de ces milices comme semblent le penser Hüseyin Baykara et Mirza Bala ? Pour eux, le parti Difai, créé dès 1905, prend part à l'organisation de la défense des musulmans pendant la guerre arméno-tatare dans laquelle se sont effectivement opposées des milices armées par les deux camps. Et c'est la capacité et la détermination des " Turcs » à s'organiser et à s'armer efficacement qui auraient amené les Arméniens à limiter leurs actions et les dirigeants russes à rechercher des solutions de conciliation ${ }^{111}$.

Tant dans la rhétorique de son manifeste que sur le terrain, le parti affirme à la fois sa volonté de défendre les musulmans lorsqu'ils sont lésés ou menacés et son désir d'établir « une fraternité et une union effective entre les différents peuples du Caucase » et des rapports solidaires avec le parti Dašnakcutjun, dans la mesure où celui-ci dévoile honnêtement son programme, lequel ne doit pas attenter à la liberté ni à l'existence indépendante des différents peuples du Caucase ${ }^{112}$. Des rapports de 1907 décrivent les propagandistes du Difai prônant dans les différents districts des relations pacifiques avec les Arméniens ${ }^{113}$. Comme nous l'avons vu, l'action terroriste n'a pas visé de personnalités arméniennes.

\section{Parti révolutionnaire ou organisation de notables ?}

Si pour la police, le Difai appartient bien « aux partis révolutionnaires caucasiens " ${ }^{114}$, le discours est cependant plus ambivalent dans les rapports de terrain. Le chef de la police du district d'Elisavetpol' affirme bien sans ambages son caractère démocratique et ses liens avec la social-démocratie ${ }^{115}$, mais d'autres rapports adoptent un ton plus circonspect. Le gouverneur d'Elisavetpol', en août 1907, constate que le parti recrute ses membres parmi les marchands, les paysans, les étudiants, les avocats et les médecins de tendance libérale, tout en prévoyant que, dans un futur proche, il va avancer des revendications sociales et nationales plus radicales ${ }^{116}$. Džandieri, à la tête du district de Dževanšir, parle en décembre 1907 de la propagande pour une révolution agraire, mais constate qu'elle est proposée avec beaucoup de circonspection. Il évoque ensuite les réunions des arbitres de paix (mirovye posredniki) chargées de préciser et d'unifier les conditions d'application des différents usages en vigueur dans l'agriculture afin d'éviter des litiges entre propriétaires et paysans ${ }^{117}$. En revanche, tous les enquêteurs attestent de l'autorité ou de l'influence dont les militants du Difai jouissent dans la population ${ }^{118}$, ce qui explique en particulier le recours à leurs comités plutôt qu'aux autorités et institutions officielles, pour la résolution des litiges.

31 Les liens du Difai avec la social-démocratie locale ne relèvent pas de fantasmes policiers. Trois des six membres du Comité central, Karabek Karabekov, Mamed Hasan Gadžinski, Isabek Ašurbekov, viennent effectivement des rangs du parti Gummet (Himmät) ${ }^{119}$. L'organisation sociale-démocrate de ce nom, créée en 1904, ainsi que ses rapports avec le comité bakinois du POS-DR ont fait l'objet de débats historiographiques ${ }^{120}$. Irada Bagirova, se démarquant de l'historiographie soviétique azerbaïdjanaise jusqu'à une époque récente et du nouveau courant nationaliste, défend l'adhésion de ces leaders à des idées sociales-démocrates dans le contexte des premières années $\mathrm{du} \mathrm{xx}^{\mathrm{e}}$ siècle et leur 
évolution nationaliste ultérieure ${ }^{121}$. Quant au fondateur du Difai, Ahmed Agaev, des rapports de police le présentent comme un membre du Gummet, ce qui semble improbable. Mais, au vu de ses activités et de la participation de presque tous les membres du Gummet aux journaux qu'il édite, Irada Bagirova conclut que «si A.A. Agaev n'est pas un membre officiel du Gummet, il collabore cependant étroitement avec cette organisation et même au moment où il crée son propre parti « Difai » (en 1906) »122. Par ailleurs, les perquisitions effectuées chez dix membres du parti à Elisavetpol' montrent une littérature variée ${ }^{123}$. Chez Alesper Mamed-ogly Hasmamedov, avocat de profession, ont notamment été trouvés un recueil comportant les programmes des différents partis révolutionnaires russes - social-démocrate, social-révolutionnaire et constitutionnel-démocrate -, des brochures intitulées "Anarchisme et socialisme ", "Grève et boycott ", des traductions russes d'écrits de Guesde et de Lafargue, ainsi que de Kautsky ${ }^{124}$. Chez lui comme chez le président du comité du parti à Elisavetpol', Ahund-Molla-Muhamed Pišnamaz-Zade, cadi chiite de la ville, la police a relevé un appel "aux musulmans du Caucase ", imprimé en turc et en arabe à Genève en 1905, condamnant les heurts arméno-tatars qui viennent de se produire et s'en prenant au tsar et au sultan qui en sont les véritables responsables ${ }^{125}$. Cette brochure a été écrite par le militant jeune-turc Abdullah Djevdet (Cevdet) ${ }^{126}$. La littérature illégale turque arrive notamment par Kars. Un certain Nazif-Efendi Atabaš-Zade, en liaison postale régulière avec Constantinople et avec d'autres comités du Difai au Caucase, a reçu du Caire et de Paris, des journaux et de la littérature provenant du "Comité ottoman d'union et de progrès » ${ }^{127}$. Ahmed Agaev échange des lettres avec l'un des membres influents de ce comité, Bahaeddin şakir, et les idées jeunes-turques trouvent un écho dans plusieurs périodiques azéris de Baku, créés après la révolution de $1905^{128}$.

Tous ces faits, la constitution de milices ainsi que les actions terroristes revendiquées par le Difai, font bien de lui un parti révolutionnaire. Mais, lui-même se désigne comme "Comité panmusulman caucasien "Défense ». Ses leaders, au moins une bonne partie d'entre eux, ont bien approché différents partis socialistes ou libéraux et, dans certains cas, ils en ont été membres. C'est donc en connaissance de cause qu'ils choisissent le positionnement du Difai et ses modalités d'action. En fait, les membres de ce Comité sont des notables locaux. Mais, ils sont des notables ${ }^{129}$ d'un genre nouveau qui s'imposent auprès de la population locale en évinçant les autorités traditionnelles, les propriétaires terriens, les beks, comme le constatent les rapports de police ${ }^{130}$.

Presque tous les membres du comité directeur de Baku, les responsables des comités d'Elisavetpol' et de Šuša sont des diplômés de l'enseignement supérieur: Kerimbek Mehmandarov qui dirige le comité de Šuša a fait ses études de médecine à SaintPétersbourg ${ }^{131}$; Karabek Karabekov à Moscou ${ }^{132}$; Mamed Hasan Gadžinski est diplômé de l'Institut technologique de Saint-Pétersbourg ${ }^{133}$; Ahmed Agaev, venu poursuivre ses études à Paris, y a participé, au début des années 1890, à la vie intellectuelle en publiant des articles dans diverses revues ${ }^{134}$; l'ingénieur Bejbut Dževanširskij a parachevé sa formation en Angleterre et en Allemagne ${ }^{135}$.

Ils occupent des positions de notables et participent à la vie publique et culturelle comme animateurs des sociétés de bienfaisance ou de propagation de l'enseignement, comme conseillers des doumas urbaines de leurs villes ou comme fondateurs de journaux turcophones de Baku et journalistes. Certains sont issus de familles reconnues comme nobles par l'administration russe, tels Isabek Ašurbekov, membre de l'une des seize familles de beks héréditaires de l'ancien khanat indépendant de Baku, et de surcroît 
propriétaire de terrains pétrolifères ${ }^{136}$, ou Alesker Mamed-ogly Hasmamedov, avocat d'Elisavetpol' comme son frère, Halil-bek, député du gouvernement d'Elisavetpol' à la II ${ }^{\mathrm{e}}$ Douma et représentant les gouvernements de Baku, d'Elisavetpol' et d'Erevan à la III ${ }^{\mathrm{e}}$ Douma. Appartient également à la noblesse, Ismail Zijathanov, député d'Elisavetpol' à la Première Douma, élu en mars 1907 à la tête de l'« Union transcaucasienne musulmane » lors du congrès du Difai de mars $1907^{137}$. Le comité de Gandja est dirigé par Ahund-MollaMuhamed Pišnamaz-Zade, président de l'assemblée (medžlis) chiite du gouvernement d'Elisavetpol', qui va ensuite poursuivre sa carrière à Tiflis, à la direction spirituelle chiite de Transcaucasie ${ }^{138}$. Il est secondé par Alekperbek Rafibekov (Ali Ekper Rafaibeyli), d'une famille très connue à Gandja, décrit comme droit, courageux, puissant et écouté du peuple par Mirza Bala et Naki Keykurun qui lui assignent un rôle de premier plan ${ }^{139}$. Le congrès du Difai de mars 1907 se tient dans la maison du maire d'Elisavetpol', Asker-Aga Adygezalov ${ }^{140}$.

Ces fils de notables se distinguent nettement des élites traditionnelles musulmanes. $\mathrm{Au}$ cours des études qu'ils ont effectuées dans des écoles russes, parfois en dépit de l'opposition de leur milieu ${ }^{141}$, ils ont été influencés par les idées populistes ou socialistes de leurs maitres ${ }^{142}$. Certains ont organisé des cercles étudiants populistes ou socialistes. C'est le cas, par exemple, d'Asker-Aga Adygezalov ${ }^{143}$. Les rassemblements de la population, organisés par les membres des sociétés de bienfaisance et les marchands de Šuša dans les villages du gouvernement d'Elisavetpol', dont le rituel a été décrit précédemment, pourraient s'inspirer de «la marche au peuple» de l'été 1874 dans les campagnes de la Russie centrale. Ce substrat populiste se conjugue à des tendances politiques d'apparition plus récente. Parmi elles, le courant social-fédéraliste géorgien milite pour des relations fédérales entre la Russie et la Transcaucasie et l'organisation de cette dernière sur des bases fédératives, objectifs que reprennent le Comité socialfédératif turc et le parti Gejrat [Honneur], créés à Gandja en 1905. Deux des chefs du Gejrat deviennent des leaders du comité du Difai de la ville : le charismatique Alekperbek Rafibekov et l'avocat Alesker Mamed-ogly Hasmamedov ${ }^{144}$.

Le recrutement du Difai parmi les élites et son ancrage révolutionnaire sont des caractéristiques qu'il partage avec de nombreuses organisations politiques de Transcaucasie et plus généralement de Russie. Un trait paraît sans doute plus singulier : les méthodes adoptées par ses membres, l'endoctrinement de la population, le recours au terrorisme ciblé et le recrutement de milices armées ne constituent pas leur mode d'action exclusif. En effet, ces mêmes leaders ou d'autres acteurs de la vie publique appartenant aux mêmes réseaux qu'eux tentent d'agir par des moyens légaux et traditionnels. Par exemple, tant une requête, présentée au vice-roi en juillet 1906 par une délégation dirigée par le cheikh-ul islam, le plus haut dignitaire chiite de la Transcaucasie, qu'une résolution du III $^{e}$ Congrès de l'Union des musulmans russes (16-21 août 1906) ont demandé le rappel du général Gološčapov de Šuša ${ }^{145}$. La décision d'attenter aux jours de ce dernier est prise par des membres du Difai en contact avec les auteurs de ces requêtes et qui décident d'adopter des procédés plus radicaux. De même, Ahmed Agaev a fait partie de la délégation qui s'est rendue à Saint-Pétersbourg en avril 1905 pour présenter la « pétition des musulmans du Caucase » au Conseil des ministres ${ }^{146}$, et Alesker Hasmamedov, de la députation de la ville d'Elisavetpol' envoyée à Tiflis en août 1905 pour obtenir du vice-roi la confirmation des élections municipales de la ville ${ }^{147}$. Une requête soutenue par un membre du comité central du Difai, en l'occurrence Karabek Karabekov, à l'époque où ce parti est le plus actif, atteste bien de l'emploi concomitant de modes de pression légaux et de moyens d'actions clandestins et hors-la-loi par les 
mêmes personnes : il s'agit de la note de février 1907 demandant une subvention d'aide aux victimes de la faim dans le gouvernement d'Elisavetpol' et la protection des nomades lors de leur transhumance ${ }^{148}$. Cette même année, Ahmed Agaev s'est rendu à Saint-Pétersbourg où il a obtenu le rejet d'un projet d'expulsion de la population musulmane hors de certains territoires proches des puits pétrolifères des environs de $\mathrm{Baku}^{149}$.

Au sein d'élites progressistes aux engagements politiques protéiformes, le Difai apparaît à la fois comme un groupement d'intérêt, un lobby de notables, et une organisation révolutionnaire. Cette organisation poursuit deux buts de nature différente: l'un, de défense et de dissuasion dans le conflit arméno-tatar, particulièrement au Karabah, l'autre, de constitution d'une base populaire au sein de laquelle elle acquiert de l'influence et de l'autorité et qu'elle pourrait mobiliser à un stade ultérieur. Ces deux aspects sont liés dans la mesure où les actions violentes que le Difai mène disposent favorablement à son égard une population, plus encline de ce fait à participer aux rassemblements organisés sous son égide et à le soutenir. Les rapports de police locaux voient comme résultat de son action la plus grande cohésion, l'union (spločenie), des communautés que l'organisation approche ${ }^{150}$.

Il est intéressant d'observer la répression menée contre le Difai par les autorités tsaristes. En mars 1908, arrive de Tiflis l'ordre d'éloigner du Caucase les chefs du parti, du moins ceux connus de la police ${ }^{151}$. Et le gouverneur d'Elisavetpol' qui reçoit la résolution secrète lui enjoignant d'engager la répression explique pourquoi les membres du parti n'ont pas été encore arrêtés. Son prédécesseur, dit-il, avait à liquider le parti révolutionnaire arménien Dašnakcutjun avant de s'attaquer au Difai, "pour que l'arrestation simultanée des membres de ces deux organisations révolutionnaires ne suscite leur opposition unie contre le gouvernement $»^{152}$. Non seulement la répression contre le Difai est reportée de plusieurs mois, mais elle se révèle assez limitée. Elle vise d'abord Ahmed Agaev. Ce dernier émigre en Turquie, soit dès le printemps 1908 pour éviter son arrestation ${ }^{153}$, soit à la fin de 1908 ou au début de 1909, après la révolution ottomane et l'accession au pouvoir des Jeunes-Turcs ${ }^{154}$, soit encore en juin 1909 comme l'annonce un journal de Tiflis ${ }^{155}$. La répression atteint une douzaine de personnes de la ville de Šusa ou de villages des districts proches, qui sont internées en mars 1908 dans la prison de cette ville, ainsi qu'un Persan nommé Mešadi Memed Džafar Muhtarov y résidant également (agent du consulat de cette ville, il aurait dirigé l'activité du parti dans les districts de Zangezur et de Džebrail). Une dizaine d'activistes de Gandja sont également inquiétés. La répression se solde par des mesures d'expulsion vers le gouvernement d'Astrahan' d'un certain nombre des détenus de Šusa qui, finalement, restent dans leur ville, moyennant des engagements et le dépôt de 3000 roubles au Trésor pour chacun d'entre eux, par l'expulsion en Iran de Muhtarov et, enfin, par l'exil de deux citoyens de Gandja, l'un à Samarkand, l'autre à Bahčisaraj, en Crimée ${ }^{156}$.

En revanche, les membres des comités directeurs du parti, en dehors d'Ahmed Agaev, ne sont pas inquiétés. Dans le cas d'Elisavetpol', les notables qui ont été membres ou sympathisants du parti poursuivent leur carrière: Asker-aga Adigezalov demeure maire de la ville jusqu'à sa mort en 1910; Alekperbek Rafibekov, Alesker Mamed-ogly Hasmamedov, Mešadi Ali Rafief et Gamidbek Usubbekov ont tous été membres du comité local du Difai et ils restent conseillers à la douma urbaine; Ahund-MollaMuhamed Pišnamaz-Zade est même promu à la tête de la Direction spirituelle chiite de Transcaucasie ${ }^{157}$. De la même façon, le président du comité du Difai de Šuša conserve ses 
fonctions de médecin responsable de la santé du district ${ }^{158}$. Plusieurs d'entre eux restent cependant suspectés et sont, en 1911-1912, l'objet de tracasseries policières menées au nom de la lutte contre le " panislamisme ${ }^{159}$. La modération des mesures de répression de 1908-1909 s'explique sans doute par des considérations stratégiques tenant compte du rôle et du prestige dont les notables membres du parti jouissent auprès de la population ${ }^{160}$.

Ces notables, au mode de vie européanisé pour la plupart, connaissent de l'intérieur la société locale qu'ils cherchent à faire évoluer non pas de façon révolutionnaire, mais dans une optique réformiste. Le programme de l'Assemblée du Karabah pour l'union, tout en s'appuyant sur les prescriptions de la charia et de la loi et en tentant de faire évoluer la coutume, impose des choix réformistes dans plusieurs domaines. Dans celui de l'enseignement, il recommande l'ouverture d'établissements pour les garçons et pour les filles professant la " nouvelle méthode » (art. 34). En matière d'encadrement spirituel, il s'en prend aux pišnamaz (ceux qui mènent la prière), cadis, prédicateurs et autres qui interpréteraient les dogmes de l'islam faussement et de façon à satisfaire le gouvernement (art. 44) ${ }^{161}$ et il impose son contrôle sur l'utilisation des fonds des vakuf (waqf), biens inaliénables des mosquées et fondations pieuses (art. 50) ${ }^{162}$. Ce réformisme musulman a été moins étudié en Transcaucasie que dans d'autres régions de l'Empire russe - dans lesquelles le mouvement djadid a été mis en exergue et réévalué -, le courant laïcisant et anticlérical qui s'est manifesté précocement dans une partie de l'intelligentsia azerbaïdjanaise ayant davantage retenu l'attention des historiens. Mais, il est cependant l'un des courants à l'œuvre dans cette société complexe ${ }^{163}$. Le programme de l'Assemblée du Karabah pour l'union revient très souvent sur le reversement aux pauvres d'une partie des sommes prélevées par le parti à titre de cotisations ou d'amendes. Ces pratiques obéissent à des prescriptions musulmanes sur l'aumône (zakat). Elles peuvent aussi relever de conduites caractéristiques des notables iraniens, incarnant chacun à leur manière l'idéal de « l'homme intègre » (javânmard) ${ }^{164}$.

\section{Autodéfense et milices : contextualisation de l'action politique et de la violence}

Dans quel contexte socio-politique le parti Difai a-t-il été créé ? Que représente, dans la Transcaucasie du début du $\mathrm{xx}^{\mathrm{e}}$ siècle, la levée de milices fortes de 900 hommes, de 400 combattants dans celle de Šuša, de 50 à 100 hommes dans les bandes constituées auprès des autres comités du parti ${ }^{165}$ L'organisation du parti, rappelons-le, est directement liée à la "guerre arméno-tatare». Celle-ci a été l'objet de récits et d'analyses diamétralement opposées qui ne seront pas exposées ici. Elle consiste en des heurts dans différentes villes et régions dont le déroulement en 1905 peut être schématisé ainsi : Baku (6-9 février, puis 20-25 août), Erevan (20-23 février, puis 23-26 mai), Nahičevan (12-15 mai), Džebrail et villages des alentours (juin), Šuša (16-20 août), Zangezur (de la fin août à décembre), Dževanšir et villages de la région (septembre), Elisavetpol' (18-25 novembre), Tiflis (23 novembre- ${ }^{\text {er }}$ décembre) ${ }^{166}$. Dans certaines régions rurales, les violences éclatent lors de la traversée des piémonts par les nomades ${ }^{167}$ qui se rendent chaque année avec leurs troupeaux des plaines vers les montagnes pour les pâturages d'été (ejlagi) et regagnent les régions basses pour les pâturages d'hiver (kišlagi). Le prince Napoléon $^{168}$, alors gouverneur d'Erevan, fait une déclaration sur les attaques de villages arméniens par les nomades lors de leur montée vers le Zangezur et sur les routes de 
retour vers les districts de Šuša et de Dževat (gouvernement de Baku) ainsi que sur son action pour les contenir ${ }^{169}$. En 1906, du 20 février au 6 mars, le vice-roi réunit à Tiflis un congrès au cours duquel les délégués musulmans et arméniens doivent s'entendre sur les mesures à prendre pour faire cesser les massacres ${ }^{170}$. Mais, au printemps de cette annéelà, les nomades qui veulent gagner les montagnes du Karabah trouvent les routes qu'ils empruntent habituellement obstruées et une grande partie d'entre eux doit renoncer à l'estivage. Ceux qui s'y risquent se font attaquer et tuer dans le défilé d'Askeran qu'ils doivent emprunter, ce qui rallume les violences à Šuša et ailleurs. Des combats entre milices armées, des pogromes dans des villages avec extermination de toute leur population et incendies ont encore lieu l'été $1906^{171}$. Il n'y a pas eu de bilan officiel des victimes humaines et des pertes matérielles de ce conflit. Aknouni fait état de la destruction de 286 villages, 128 habités par des Arméniens, 158 par des « Turcs » et des préjudices causés à 14760 familles, 7265 arméniennes, 7495 « tatares » ${ }^{172}$. Swietochowski reprend ces chiffres pour la destruction des villages et donne pour le nombre de tués des estimations allant de 3100 à $10000^{173}$. Pour le seul gouvernement d'Elisavetpol', la consultation des documents officiels annuels le concernant permet une approximation de l'ordre de 3400 tués, 3100 hommes et 300 femmes $^{174}$.

43 La poursuite de la transhumance des nomades oppose de fait Arméniens et musulmans. En 1906, les routes de transhumance qui passent auprès ou dans des villages arméniens sont fermées, non seulement sur l'initiative de villageois excédés des perturbations ou des exactions qui se produisent lors du passage des nomades et de leurs troupeaux, mais aussi selon une stratégie délibérée inspirée par les Dašnaks. Lors de la conférence régionale du parti (novembre 1905), Amazasp, le délégué de Šuša, revient à deux reprises sur le plan de priver les nomades d'accès à la montagne au printemps, plan qui ne fait pas l'unanimité175. Lors du congrès de février-mars 1906 de Tiflis, les délégués arméniens et musulmans défendent des positions différentes puis s'entendent finalement sur la création d'une commission spéciale sur cette question ${ }^{176}$. L'intelligentsia musulmane de tous bords se mobilise pour le maintien des pratiques de transhumance des nomades, maintien vital en raison de l'insalubrité des plaines en été (chaleur torride, malaria, épizooties), y compris le député musulman du gouvernement d'Erevan à la $\mathrm{II}^{\mathrm{e}}$ Douma, Mamed Šahtahtinskij ${ }^{177}$.

Que représentent les nomades dans le gouvernement d'Elisavetpol' à cette époque? Il n'est pas simple de répondre à cette question car peu d'études scientifiques ont été consacrées au nomadisme en Azerbaïdjan, hormis le remarquable article de Deljara Ismail-Zade qui porte sur la première moitié du xixe siècle et donne aussi des données de 1896 et $1898^{178}$. L'auteur dresse deux cartes, l'une localisant les pâturages d'été et ceux d'hiver avant 1850, l'autre consacrée aux pâturages d'été du Karabah appartenant à l'État et montrant leur attribution à des habitants des districts de Džebrail, de Dževanšir, d'Elisavetpol', de Zangezur, de Šusa, et de Dževat au début des années $1880^{179}$. Ces cartes permettent de comprendre pourquoi l'obstruction des voix d'accès aux pâturages du Karabah a des répercussions dans cinq districts qui sont ceux où le parti Difai s'est implanté. C'est parce que le défilé d'Askeran donne accès aux pâturages d'été du Karabah qu'il est un lieu névralgique occupé en 1905-1906 par une bande armée arménienne ${ }^{180}$ et que l'acquisition de terrains à peupler exclusivement de musulmans entre Agdam et Hodžaly fait partie du programme d'action du Difai (mars 1907). La plupart des "nomades" sont aussi des cultivateurs dans leur lieu de résidence principale et 
l'administration du gouvernement d'Elisavetpol' prône la sédentarisation progressive des nomades ${ }^{181}$.

À propos de l'encadrement et de la protection des nomades, la presse et une requête adressée au vice-roi donnent quelques éléments intéressants. Dans sa déclaration de septembre 1905, le prince Napoléon mentionne 500 cavaliers persans et 1200 cavaliers kurdes du Zangezur qui auraient dû protéger les nomades durant l'estivage et le retour vers les plaines et que des mesures judicieuses ont amenés à repasser la frontière pour les premiers, à se disperser pour les seconds ${ }^{182}$. Il est bien question de Persans et de Kurdes dans la requête que le Comité spécial d'aide aux musulmans de Transcaucasie victimes de la famine a adressée au vice-roi, en février 1907, mais dans le rôle de prédateurs et non de protecteurs des nomades. Dans cette requête, sont évoqués les dangers qu'encourent les nomades sur les routes, du fait « des bandes nombreuses de bandits et de toutes sortes d' "éléments louches" (temnye elementy), dont les effectifs se renforcent en été de pillards persans et des nôtres, majoritairement kurdes $»^{183}$. Il y est expressément demandé d'autoriser les nomades à porter des armes pour leur autodéfense.

C'est également au nom de l'autodéfense des Arméniens qu'à partir de 1903, le parti Dašnakcutiun a organisé la lutte révolutionnaire armée au Caucase, suivant des procédés et des méthodes déjà éprouvées en Anatolie, depuis sa création à Tiflis en 1890 et son premier congrès tenu à Genève en $1892^{184}$. La militarisation de toutes les composantes du mouvement révolutionnaire arménien, les préoccupations militaires des dašnaks frappent les spécialistes de ce mouvement ${ }^{185}$. Dans le contexte caucasien du début du $\mathrm{xx}^{\mathrm{e}}$ siècle, c'est toujours au nom de la défense ou de l'autodéfense que les formations politiques ou professionnelles s'arment ou demandent à le faire. Le député de la population russe de Transcaucasie à la III ${ }^{e}$ douma, Timoškin ${ }^{186}$, se plaint que les Russes n'aient pas obtenu le droit de s'armer pour leur autodéfense comme ils l'ont demandé187. Le parti ouvrier social-démocrate russe (POS-DR) organise ses "régiments d'autodéfense ", forts dans la région de Baku de 500 hommes au milieu de 1906, tout comme les SR créent des détachements mobiles, les uns et les autres se livrant à des "expropriations» (attaques de banque ou de dépôts d'armes) pour assurer leur financement ${ }^{188}$. Les discussions de la conférence régionale du parti Dašnakcutjun envisagent tour à tour défensive et attaque ${ }^{189}$.

Autre trait caractéristique de la vie caucasienne, le rôle des brigands (razbojniki). Préoccupation constante de l'administration, le brigandage a fait l'objet d'études historiques qui renouvellent profondément l'analyse de ce phénomène. Portant principalement sur le Caucase du Nord, elles concernent aussi l'Azerbaïdjan et sont consacrées aux "bandits d'honneur", appelés "abrek» dans le Nord, "kačak» en Azerbaïdjan. Vladimir Bobrovnikov, rejetant différentes analyses de l'époque soviétique faisant de ces abrek des acteurs de la lutte anticoloniale, historicise le phénomène en montrant comment le brigandage s'est développé du fait de la criminalisation de pratiques qui, avant la conquête russe, utilisaient la menace de la violence pour prévenir son escalade ${ }^{190}$. Ces mêmes kačak, qui sont souvent des hors-la-loi vivant dans la clandestinité pour échapper au bagne auquel ils ont été condamnés, sont actifs dans les années 1880 et au début du $\mathrm{xx}^{\mathrm{e}}$ siècle dans les contreforts du Grand Caucase (région de Kuba, Nuha) et dans les montages du Petit Caucase ${ }^{191}$. Les milices au service du Difai utilisent leurs services. Certains kačak apparaissent dans les relations des heurts arménotatars et dans les récits sur le parti Difai, mais dans des rôles inattendus. L'un d'eux est Dali (ou Deli) Ali, mort en 1913 à l'âge de quatre-vingts ans. Sa bande a été active de 
nombreuses années dans les montagnes du nord de l'Azerbaïdjan, du sud de la Géorgie et du Daghestan ${ }^{192}$. En août 1905, dans la région de Šuša, à la tête de plus de cent bandits, Dali Ali empêche une troupe de Tatars d'attaquer des villages arméniens et l'oblige à se disperser ${ }^{193}$. Le récit de Naki Keykurun met en scène Deli Ali, à la tête de 2000 hommes, à Gandja, renonçant à l'attaque projetée de positions arméniennes ${ }^{194}$. Ces récits, comme celui de Baykara ${ }^{195}$, présentent Deli Ali dans des situations de réserve où, dans un cas, il s'interpose entre des combattants et, dans le second, il se soumet à une décision d'abandon d'une opération armée projetée. Un autre de ces bandits d'honneur, le kačak Zaid (Ekihanskij), exerce l'autorité dont il jouit dans la région de Geökčaj (gouvernement de Baku) pour prévenir des heurts qui auraient pu s'y produire entre Arméniens et musulmans. Après avoir vécu dix ans dans la clandestinité, Zaid avait gagné Istanbul. Il en revient à la demande des représentants des deux nations et remplit efficacement sa mission de paix, achevée en août 1906. Zaid n'obtient pas l'amnistie que son action aurait pu justifier ${ }^{196}$, alors que Dali Ali est gracié par Nicolas II après avoir sauvé, l'été 1906, le domaine viticole du prince Golicyn, l'ancien gouverneur et commandant en chef du Caucase $^{197}$. Les forces de l'ordre mènent des expéditions punitives contre les bandits et contre les villageois qui les accueillent après leurs mauvais coups. Mais, dans certaines circonstances, elles les laissent faire ou essaient d'utiliser l'un de ces kačak pour en capturer un autre ${ }^{198}$.

Tous ces éléments constitutifs de la société de Transcaucasie doivent conduire à banaliser la levée de milices, fortes au total de 900 hommes, par le parti Difai. La défaite de la Russie dans la guerre russo-japonaise, l'envoi de troupes sur le front d'ExtrêmeOrient et la concentration de forces à Baku pour la protection des exploitations pétrolières ${ }^{199}$ ont créé des conditions favorables à une recrudescence du banditisme et au développement des tensions ou conflits interethniques. L'administration use de sa force et compose avec les différents éléments en présence. Dans son étude sur les récits de captivité au Caucase, Bruce Grant parle de « souveraineté ouverte » invitant à explorer les modes de pouvoir et d'autorité concurrents ${ }^{200}$. Tant le rôle laissé à des kačak dans les gouvernements d'Elisavetpol' et de Baku que les transactions autour des peines infligées à des membres du Difai s'inscrivent dans ce "paysage poreux ». De la même façon, de l'aveu même de la police, en 1903-1905, sous la pression du terrorisme et de la peur qu'il inspirait, dans bien des lieux, la direction ne décidait des différentes nominations et ne faisait la moindre chose concernant la population arménienne sans un accord avec les organes locaux du Dašnakcutjun ${ }^{201}$. En outre, le retour de Zaid de Constantinople va à l'encontre d'une vision de l'émigration des musulmans du Caucase vers l'Empire ottoman comme un processus sans possibilité de retour ${ }^{202}$.

Enfin, la Transcaucasie elle-même constitue une zone frontière accueillant régulièrement des Arméniens fugitifs de Turquie et impliquée dans des relations complexes avec la province iranienne d'Azerbaïdjan. Les raids de pillards Šahsevan, qui hivernaient traditionnellement dans les plaines du Mugan et qui, après la conquête russe, sont devenus majoritairement des sujets persans, entrent dans les stratégies mouvantes du pouvoir royal iranien et de ses représentants locaux et dans celles des Russes. Il semble bien que l'administration tsariste et ses représentants à Tabriz armaient certaines tribus Šahsevan tout en menant des représailles contre d'autres qui s'aventuraient trop ouvertement dans des raids au-delà de la frontière dans la première décennie du $\mathrm{xx}^{\mathrm{e}}$ siècle ${ }^{203}$. Les cavaliers ou pillards persans mentionnés en protecteurs ou attaquants des 
nomades sont très certainement des Šahsevan et leurs raids sont fréquents dans le district de Džebrail à l'époque de la révolution constitutionnelle iranienne (1905-1909) 204 .

Le parti Difai, armé comme tant d'autres acteurs de la vie sociale et politique, développe son action dans le contexte d'une souveraineté russe affaiblie. Les défaites infligées par le Japon et les actions révolutionnaires locales créent un climat où peurs et rumeurs se diffusent très vite. Parmi les scénarios montés dans l'un ou l'autre camp, nous retrouvons d'une part celui d'une domination arménienne, d'autre part celui d'un pouvoir musulman restauré et d'un panislamisme menaçant ${ }^{205}$. Ces scénarios alimentent débats ou polémiques dans la presse et influencent l'opinion publique. En ce qui concerne l'intelligentsia musulmane de Transcaucasie, elle privilégie l'action légale et conserve l'espoir que le vice-roi Voroncov-Daškov réussisse à faire passer certaines réformes telles l'introduction des zemstva au Caucase et l'abolition des discriminations à l'égard des nonchrétiens. Après le départ d'Agaev pour la Turquie en 1908-1909, une partie de l'intelligentsia a encore assez confiance dans le pouvoir, pour envisager d'adresser une pétition ou d'envoyer une délégation, à la fin de 1911, afin d'obtenir l'intervention du gouvernement russe dans la guerre italo-turque pour qu'il impose la paix, indispensable aux Turcs. Cependant, l'abandon de cette requête sur le conseil de Toptchibachy ${ }^{206}$ et la création clandestine du parti Musavat cette même année laissent penser que, désormais, la défiance et le mécontentement prévalent ${ }^{207}$.

51 Enfin, il est utile de replacer la violence et l'action politique locales dans le contexte russe. Les analyses récentes sur la première révolution russe et sur les mouvements et partis politiques des années 1905-1907 montrent que l'ensemble des organisations politiques de Russie ne regroupait pas plus de $0,5 \%$ de la population du pays. Elles mentionnent à la fois la diffusion rapide d'une idéologie socialiste, radicale marxiste ou néo-populiste, et l'implantation dans toutes les classes de la société, y compris chez les paysans et les ouvriers, d'organisations d'extrême-droite ${ }^{208}$. Elles mettent en exergue l'incompréhension entre l'intelligentsia qui anime les différents partis et les masses et soulignent l'importance des revendications locales présentées par des paysans et ouvriers aspirant à une plus grande autonomie de leurs propres organisations ${ }^{209}$. Un ensemble d'événements violents de 1905 font de cette révolution non seulement « la répétition générale d'Octobre ", mais le " prologue et le prototype de la guerre civile de 1917-1922 $»^{210}$. Dans ce contexte général, le Caucase occupe une place bien particulière, du fait d'une politisation précoce et relativement forte des Arméniens et des Géorgiens, de l'intensité des conflits tant sociaux qu'interethniques et des représentations et des passions qu'il suscite, particulièrement dans les milieux conservateurs et ultranationalistes russes. Ainsi, la prise en compte des rapports réciproques complexes entre les utopies socialistes et nationalistes et des possibilités de manipulation reposant sur diverses combinaisons d'éléments empruntés aux unes et aux autres ${ }^{211}$, amènent à relativiser l'impression d'étrangeté que peut laisser la description de l'organisation, des plans et des modes d'action du Difai.

\section{Représentations et constructions idéologiques}

Comment, dans les camps révolutionnaire et conservateur, sont perçus les musulmans de Transcaucasie, leur participation aux mouvements politiques ou nationaux qui se développent avec la révolution de 1905 et après? 

auteurs mencheviks, consacre une partie de son quatrième tome "aux mouvements nationaux $»^{213}$. Pour la Transcaucasie, seuls sont décrits les mouvements nationaux arméniens et géorgiens. Ceux des musulmans du Caucase ne sont pas du tout mentionnés. Les «Tatars» de Transcaucasie y sont décrits comme les " plus grands capitalistes de la région », des « khans et des beks » qui détiennent la majeure partie des terres. Sont aussi évoquées les masses tatares incultes du Lumpenprolétariat. La négation de tout mouvement national musulman en Transcaucasie va de pair avec une présentation de la guerre arméno-tatare comme une lutte organisée précisément comme diversion au mouvement révolutionnaire arménien et dont la grande majorité des victimes seraient arméniennes ${ }^{214}$. Cette somme reprend des représentations qui vont perdurer dans l'historiographie de la Transcaucasie. Zalevskij présente de façon beaucoup plus favorable les musulmans de la région de la Volga et les Kirghiz (Kazakhs), leur prise de conscience nationale, leurs pétitions et leurs organisations ${ }^{215}$. Or, aux différents stades de la révolution de 1905-1907, les musulmans des régions de la Volga, de Crimée et de Transcaucasie réagissent aux événements en cours et prennent des initiatives en phase les unes avec les autres ${ }^{216}$.

(lie du Caucase » (Kavkazskij zapros) peut être utilisé pour caractériser les perceptions sur ce territoire et sur ses nationalités, sous-tendant les déclarations des députés de tous bords. L'interpellation présentée par 38 députés d'extrême droite " au sujet des actes terroristes au Caucase " et discutée lors de cinq séances de la III ${ }^{e}$ Douma (décembre 1908-février 1909) ${ }^{217}$ s'en prend à la politique menée par Voroncov-Daškov, l'accusant d'encourager les mouvements révolutionnaires et séparatistes et de ne pas servir les intérêts russes. Les dix députés du Caucase, ainsi que des membres des diverses fractions de la Douma et deux représentants du vice-roi lui-même, interviennent lors de ces séances. En dehors des députés musulmans eux-mêmes, aucun des intervenants, ni les sociaux-démocrates géorgiens, ni les constitutionnels-démocrates russes, ne mentionnent la participation spécifique des musulmans au « mouvement de libération ». Les revendications pour la fin des discriminations à l'égard des non-chrétiens, pour une politique de colonisation ne les dépossédant plus de leurs terres ancestrales, pour une pratique libre de leur religion et pour des réformes dans le domaine de l'éducation, de la justice et de la santé publique, sont rappelées par Hasmamedov, dans des termes qui sont précisément ceux de la pétition des musulmans du Caucase, mais par lui-seul, au cours de ces séances ${ }^{218}$.

Aux vieux clichés sur les peuples sauvages et incultes du Caucase, sur la mission civilisatrice russe, s'ajoutent de nouveaux clivages liés à la plus ou moins grande participation au mouvement révolutionnaire. La politisation extrême de conflits nationaux est l'une des caractéristiques des années 1905-1907, particulièrement pour les pogromes des gouvernements du Sud-Ouest dirigés contre les juifs en raison de leur rôle présumé dans la révolution et pour les heurts arméno-tatars de Transcaucasie ${ }^{219}$. Les musulmans se trouvent à la fois victimes de préjugés contre l'islam et contre leur détermination à défendre leur religion et d'un certain rejet pour leur moindre participation à la révolution de 1905 . Une vision répandue des massacres arméno-tatars leur porte préjudice. À la tribune de la III ${ }^{e}$ Douma, Hasmamedov rappelle que les journaux arméniens, la presse russe de droite et, hélas, un des organes progressistes, Rus' nommément, ont expliqué ces heurts par le panislamisme, mouvement qui serait basé sur le fanatisme musulman et constituerait une tentative des musulmans d'anéantir la 
culture européenne et le monde chrétien. Et, il cite les prescriptions du Prophète à l'égard des autres religions ${ }^{220}$, même si ces références au Coran détonnent quelque peu dans l'hémicycle du palais de Tauride.

À la quasi-négation de tout mouvement national musulman au Caucase va succéder un ostracisme à l'égard du parti Musavat, lequel allie en fait islam, socialisme et nationalisme. Son accession au pouvoir en Azerbaïdjan en 1918 oblige à le prendre en considération. Ce parti est perçu comme un ramassis de "beks et de khans", de nouveaux riches capitalistes et de chauvinistes haineux. Et ces accusations sont reprises dans la littérature historique et les mémoires de différents protagonistes - bolcheviks, mencheviks, SR, KD et partisans de Denikin -, voyant dans ce parti une poignée d'intellectuels et d'aventuriers musulmans, régnant sur des masses ignorantes et inertes. M.G. Smith lie ces perceptions et la création et la circulation de rumeurs leur donnant corps à des préjugés « impériaux » et " orientalistes » sur l'arriération, la tricherie et le fanatisme religieux des musulmans ${ }^{221}$.

Depuis la restauration de l'indépendance de l'Azerbaïdjan en 1991, une nouvelle historiographie nationale s'écrit à partir de sources revisitées. Le Difai y a trouvé une place. Mais, sans doute en raison d'a priori sur la construction nationale azerbaïdjanaise et de susceptibilités nationales exacerbées par la détérioration des relations entre l'Arménie et l'Azerbaïdjan (sécession du Haut-Karabah en 1991, occupation de territoires azerbaïdjanais limitrophes du Haut-Karabah, combats jusqu'à la signature d'un cessez-lefeu en 1994, tension persistante), certaines particularités de ce parti sont esquivées. Le rôle du Difai comme facteur de cohésion nationale ne peut se comprendre que si l'identité nationale est conçue comme un processus en construction et non comme une donnée intangible. La production d'un discours mythifié sur l'histoire nationale, faisant de l'antagonisme avec les Arméniens une donnée permanente et primordiale, se reflète dans certaines pages des ouvrages d'Irada Bagirova et d'Eldar Azizov, bien que l'un et l'autre évitent les excès des livres scolaires récents et de certains auteurs ${ }^{222}$.

Le Difai a eu une courte existence, mais la plupart de ses leaders ont, après 1908, continué de participer à la vie politico-sociale au sein de doumas urbaines, d'associations professionnelles, de diverses commissions constituées pour la mise au point de réformes et de sociétés de bienfaisance et d'encouragement de l'enseignement. Après février 1917, à l'issue de réunions à $\mathrm{Baku}(16,22$ mars), un Comité provisoire des organisations sociales musulmanes est institué. Deux des anciens membres du Comité central du Difai, Mamed Hasan Gadžinskij et Bejbut Dževanširskij, font partie de son bureau national ${ }^{223}$. Le Premier Congrès régional des musulmans du Caucase (15-20 avril 1917) à Baku, réuni dans l'immeuble de la Société musulmane de bienfaisance et présidé par Toptchibachy, se prononce d'une part pour l'instauration en Russie d'une république démocratique et son organisation territoriale fédérative et, d'autre part, pour la fin de la guerre sans annexions ni contributions ${ }^{224}$. À l'instar du Difai, ce congrès veut agir dans deux directions : l'organisation des forces et l'éducation des masses. Il adopte de nouvelles institutions religieuses, instaurant une direction spirituelle unique pour les sunnites et les chiites ${ }^{225}$, achevant en cela le programme du Difai de dépassement des clivages religieux et appelant à l'union de tous les courants politiques. Le Difai, en tant que parti, réapparaît d'ailleurs à Gandja en 1917 puis rejoint le Musavat ${ }^{226}$. Au même moment, est lancé à Elisavetpol' le Parti turc des fédéralistes en Russie, auquel s'inscrivent rapidement 500 personnes ${ }^{227}$. Son programme prévoit l'établissement d'une république démocratique selon les principes nationaux, territoriaux et fédératifs pour toute la 
Russie et, en particulier, l'autonomie territoriale pour l'Azerbaïdjan, le Turkestan, la Kirghizie et la Bachkirie, et l'autonomie nationale pour les Tatars de la Volga et de Crimée et pour toutes les nationalités turques en général. Ce « parti turc des fédéralistes en Russie» fusionne en juin 1917 avec le parti Musavat, pour former le parti démocratique turc des fédéralistes "Musavat ${ }^{228}$. Dans le comité central de ce nouveau parti, on trouve Mamed Hasan Gadžinskij et deux personnalités de Gandja, Nasib bek Usubbekov ${ }^{229}$ et Hudadat Rafibekov ${ }^{230}$, appartenant l'un et l'autre à des familles dont des membres ont milité au Difai. Ce parti, local et " panmusulman ", a bien constitué l'un des acteurs du mouvement national azerbaïdjanais, encore à un stade embryonnaire dans les années 1906-1908. En 1917, le mouvement national azerbaïdjanais s'affirme au sein d'un nouvel État russe démocratique et élabore ses projets pour les musulmans de toute la Transcaucasie, ceux des gouvernements de Baku, Elisavetpol', Erevan, Tiflis, Kars, Batumi et du Zakatala. Ce mouvement, dont le champ territorial d'action va évoluer en fonction des événements politiques et militaires, se conçoit lui-même comme l'une des composantes de la vie politico-sociale de la Transcaucasie ou du Caucase multiethniques et comme une partie d'une entité islamique plus large. Lors du Congrès musulman du 15-20 avril 1917, est adoptée une résolution concernant les femmes et affirmant leurs droits sociaux, politiques et citoyens ${ }^{231}$. Rasul Zade y explique l'importance du rôle des femmes dans le mouvement national en se référant explicitement aux autres nationalités ${ }^{232}$.

S'il est relativement facile de suivre les parcours politiques des leaders du Difai, sur la scène très mouvante de la Transcaucasie des années 1917-1922 ou en Turquie dans le cas d'Ahmed Agaev, et leurs évolutions ultérieures, il est en revanche beaucoup plus difficile de connaitre l'impact de son action au sein des communautés rurales des différents districts du gouvernement d'Elisavetpol' au-delà de 1908 car l'histoire du mouvement national azerbaïdjanais reste celle de ses élites dirigeantes.

Les parcours politiques de nombreux leaders musulmans de Russie du début du $\mathrm{xx}^{\mathrm{e}}$ siècle paraissent sinueux et parfois imprévisibles, selon les critères d'analyse de la vie politique russe. Mais, dans bien des cas, ils tirent leur cohérence d'une fidélité à des valeurs nationales et à un programme progressiste qui ne s'inscrivent pas dans cette grille d'analyse. Parmi les différentes variantes de programmes progressistes, a toujours cours le slogan " turquifier, islamiser, européaniser ", popularisé dans les colonnes de la presse azérie dès 1905-1907 par l'un des théoriciens du panturquisme, Ali Bey Huseinzade ${ }^{233}$. Ces leaders qui n'ont pas joué de rôle de premier plan en Russie, ni dans la révolution de 1905-1907 ni dans celle de 1917, sont confrontés à des situations intérieures et internationales évoluant très vite à partir de 1917. Dans le cas de la Transcaucasie, les Ottomans et les Allemands, puis les Alliés interviennent par des opérations militaires et des jeux politiques divers dans la vie des républiques arménienne, azerbaïdjanaise et géorgienne proclamées en mai 1918 et dans le partage de l'Empire ottoman où se développe le mouvement kémaliste. L'histoire des années 1917-1922 a fait l'objet de différentes versions, plus ou moins mythifiées selon l'appartenance idéologique et nationale des auteurs, leur lieu de résidence en Union soviétique, dans l'émigration ou dans les républiques du Caucase à nouveau indépendantes et de travaux plus distanciés ${ }^{234}$. Elle demeure presque exclusivement l'histoire des élites. Les documents policiers sur le Difai et toute une littérature produite à la même époque par différentes institutions et acteurs ne constituent pas une heureuse exception. Bien d'autres organisations sociopolitiques du Caucase ou d'autres régions de l'espace postsoviétique pourraient être étudiées, afin d'analyser les évolutions sociales, les modalités d'intégration, de 
marginalisation ou d'élimination de communautés locales ou régionales au cours du développement de nouvelles entités nationales, dans des situations de rivalités ethniques et sociales et de transformations volontaristes.

\section{NOTES}

1. Irada S. Bagirova, Političeskie partii i organizacii Azerbajdžana v načăle Xx veka. 1900-1917 [Partis et organisations politiques en Azerbaïdjan au début du xx siècle], Baku: Elm, 1997

2. Les termes "politiques publiques», «socio-histoire", "sociologie politique» s'entendent selon l'approche des articles respectivement consacrés à ces concepts et mouvances disciplinaires par P. Hassenteufel, G. Noiriel et B. François in S. Mesure, P. Savidan, éds., Dictionnaire des sciences humaines, P.: PUF, 2006, p. 861-863 ; 1101-1103; 1112-1114.

3. Voir P.V. Volobuev, éd., Revoljucija i čelovek: Social'no-psihologičeskij aspekt [La révolution et l'homme: aspect socio-psychologique], M. : IRI RAN, 1996; Revoljucija i čelovek: Byt, nravy, povedenie, moral' [La révolution et l'homme: vie quotidienne, mœurs, conduite, morale], M. : IRI RAN, 1997.

4. V.P. Buldakov, «Rossijskie smuty i krizicy : Vostrebovannost' social'noj i pravovoj antropologii [Troubles et crises russes : le recours à l'anthropologie sociale et juridique], Rossija i sovremennyj mir, 2, 2001, p. 31-47.

5. E. Azizov, Difai, Istoričeskie predposylki i pričiny armjano-azerbajdžanskogo konflikta v načale $X X$ veka [ Le Difai : conditions et causes du conflit arméno-azerbaïdjanais du début du Xx siècle], Baku : Polygraphic production, 2009.

6. Je remercie tous ceux qui m'ont permis d'accéder à ces archives et à d'autres documents, en particulier: Zinaida Ivanovna Peregudova, spécialiste émérite du GARF (Gosudarstvennyj arhiv Rossijskoj Federacii - Archives d'État de la Fédération de Russie), qui y a facilité mon travail lors de mes missions en Russie de 2007 et de 2010 ; le directeur et le personnel des Archives nationales historiques de la république d'Azerbaïdjan (cidessous: GIA AR) et tout spécialement l'historienne Sudaba Zejnalova pour son aide pendant mes séjours à Baku de 2003 et de 2006; Vladimir Bobrovnikov, pour les documents qu'il m'a communiqués. Par ailleurs, j'exprime ma sincère gratitude à la rédaction des Cahiers du Monde russe pour ses conseils et pour le travail d'édition, ainsi qu'à Stéphanie Cirac pour la cartographie.

7. Bagirova, Političeskie partii, p. 171.

8. Un dossier sur cette commission et ses travaux est conservé au GIA AR, f. 524, op. 1, d. 1,2 .

9. A. Kričinski, Dokumenty po russkoj politike v Zakavkaz'e [Documents sur la politique russe en Transcaucasie], Baku: Izdanie osoboj komissii pri MID Azerbajdžanckoj respubliki, 1920, p. 5-53. 
10. Les RGIA (Rossijskij gosudarstvennyj istoričeskij arhiv - Archives nationales historiques russes) comportent certainement elles-aussi des documents sur ce parti. D.J. Arapov a publié un rapport de 1912 sur les musulmans du Caucase (RGIA, f. 821, op. 133, d. 469, p. 331-346 verso), dans Kavkazskij Sbornik, 2 (34), M.: Russkaja Panorama, 2005, p. 168-188. Sur le Difai, p. 171-173.

11. A. Ahmedov, Azerbajdžanskie Tjurki v revoljucii 1905 goda [Les Turcs azerbaïdjanais dans la révolution de 1905], Baku : Azerbajdžan Milli Enciklopedijasi, 2002, p. 267-294.

12. Ibid., p. 279-283. L'auteur cite une affaire de la section régionale caucasienne de l'Ohrana.

13. Bagirova, «Ot redaktora [Note du rédacteur] », in A. Ahmedov, Nacional'noe dviženie, partii $i$ obščestvenye dejateli Azerbajdžana $v$ 1918-1925 godah $s$ glazami očevidca [Le mouvement national, les partis et les acteurs de la vie publique en Azerbaïdjan en 1918-1925, vus par un témoin], Baku : Nurlan 2006, p. 6-7.

14. GARF, f. 102, OO (Osobyj Otdel - Département spécial), 1908, d. 296, 1. 27-39.

15. GARF, f. 102, OO, 1908, d. 296, 1. 44-83, 194-211.

16. «Dfai » et « Difai » sont des transcriptions d'un mot turc ottoman, formé à partir du verbe arabe dafa'a, repousser, défendre. "Müdafie", formé à partir du même verbe, désigne le défenseur, le résistant.

17. GARF, f. 102, OO, 1909, d. 14, l. 1-20. Ce rapport est reproduit dans E.M. Entin, éd., Političeskie partii $i$ političeskaja policija: Dokumental'noe issledovanie $v$ treh častjah [Partis politiques et police politique, recherche documentaire en trois parties], M. - Minsk Gomel', 1996, p. 401-426.

18. Deux documents établis les 3 février et 2 mars 1907 par l'ambassade ottomane à Tiflis sont publiés, transcrits en turc moderne, dans Osmanl devleti ile azerbaycan türk hanlkları arasindaki münâsebetlere daïr arşiv belgeleri. Karabağ-şuşa, Nahçivan, Bakü, Gence, şirvan, şeki, Revan, Hoy [Documents d'archives concernant les relations entre les khans türks d'Azerbaïdjan et l'État ottoman. Karabah-Šuša, Nahičevan, Baku, Gandja, Širvan, Šeki, Erevan, Hoy], II 1575-1918, Ankara : 1T.C. Başbakanlik, Devlet arşivleri genel Müdürluğu, 1993, p. 212-214.

19. Mirza Bala, Milli Azerbaycan hareketi [Le mouvement national azerbaïdjanais], Berlin : Firka Divani, 1938, p. 54-62. Mehmet Zade Mirza Bala (1898-1959), publiciste militant pour l'indépendance de l'Azerbaïdjan depuis 1915, gagne l'Iran (1923) puis la Turquie (1927) et l'Occident. Il est reconnu comme le leader du parti Musavat après la mort de Rasul Zade (1954).

20. Hüseyin Baykara, Azerbaycan istiklal Mücadesi Tarihi [Histoire de la lutte d'indépendance de l'Azerbaïdjan], Istanbul : Azerbaycan Halk Yayınları, 1975, p. 131-137. Hüseyin Baykara (1904-1984), originaire de Šuša, a émigré dans les années 1920 et mené une carrière de juge puis de procureur en Turquie.

21. A.L. Altstadt, The Azerbaijani Turks: Power and Identity under Russian Rule, Standford: Hoover Institution Press, 1992, p. 67-68, 80.

22. T. Swietochowski, Russia and Azerbaijan: A Borderland in transition, New York: Columbia University Press, 1995, p. 40-42; «National consciousness and political orientations in Azerbaijan, 1905-1920", in R.G. Suny, éd., Transcaucasia, Nationalism and Social Change, Michigan, Ann Arbor : The University of Michigan Press, 1996, p. 215-216. 
23. Naki Keykurun, Azerbaycan istiklal mucadelesinin hatıaları [Mémoires sur la lutte d'indépendance de l'Azerbaïdjan], Istanbul : Azerbaycan gençlik Derneği, 1964.

24. Tomris Azeri, petite fille de l'auteur, détient le copyright de cette traduction: The Memoirs of the National Liberation Movement in Azerbaijan, 1998 sur le site www.zerbaijan.com/azeri/tomrisbook2.html.

25. Naği şeyxzamanlı, Xatirelerin [Mémoires], Baku, 2004.

26. Azizov, Difai.

27. GARF, f. 102 OO, 1908, d.296, 1. 27-32.

28. Ibid., p. 27 verso.

29. Kričinski, Dokumenty, p. 26-27, 30.

30. GARF, f. 10200, 1907, d. 388, 1. 1-11.

31. Bagirova, Političeskie partii, p.171; V.A. Lerner, « $K$ voprosu o dejatel'nosti v Azerbajdžane buržuazno nacionalističeskoj organizacii “Difai” [La question de l'activité en Azerbaïdjan de l'organisation nationaliste bourgeoise «Difai »]», Doklady Akademii Nauk Azerbajdžanskoj SSR, t. XXXV, 1, 1979, Baku : Elm, p. 92-96, ici p. 92.

32. A. Mil'man, Političeskij stroj Azerbajdžana v xix-nač. xx vekov [L'organisation politique de l'Azerbaïdjan au xixe s. et au début du xxe s]., Baku : Az. gos. izd., 1966, p. 156-157.

33. Pervaja vseobščaja perepis' naselenija Rossijskoj Imperii, $1897 \mathrm{~g}$ [Le premier recensement général de la population de l'Empire russe en 1897], SPb.: Izd. Central'nogo statističeskogo komiteta MVD, t. LXIII, 1904, p. VII.

34. Pamjatnaja Knižka Elisavetpol'skoj gubernii na 1910 god (PKEG na 1910 g.) [Livre de l'année 1910 du gouvernement d'Elisavetpol'], Elisavetpol': Tip. Elisavetpol'skogo gubernskogo pravlenija, 1910, otdel' V, p. 3 verso, 29.

35. Ioanes Terakopov (Ivan Jakovlevič) Sagateljan (1871-1936), membre du Dašnakcutjun, est député à la $\mathrm{II}^{\mathrm{e}}$ Douma d'État où il rejoint le groupe social-révolutionnaire et à la $\mathrm{III}^{\mathrm{e}}$ Douma (groupe travailliste). Il travaille à partir de 1921 au Commissariat du peuple à l'Agriculture de la RSS d'Arménie.

36. Stenografičeskij otčet. Gosudarstvennaja Duma Tretij sozyv (SOGD 3soz.) [Compte-rendu sténographique. Douma d'État, $3^{e}$ législature], Sessija II, Č. II, zasedanie 46, 4 février 1909, $\mathrm{SPb}$ : Gos. Tip., 1909, col. 872.

37. Sur ces questions territoriales, voir A. Cuciev, Atlas Etnopolitičeskoj istorii Kavkaza (1774-2004) [Atlas de l'histoire ethnopolitique du Caucase], M.: Evropa, 2006, en part. p. 30-33, 48-64, 66. Voir aussi V.N. Hudadov, Zakavkaz'e, Istoriko-ekonomičeskij očerk [La Transcaucasie. Essai historico-économique], M. - L. : Central'noe upravlenie pečati VNSH SSSR, 1926, p. 60-64.

38. Ces chiffres sont établis à partir du recensement de 1897, Pervaja vseobščaja perepis', t. LXIII, p. 1, 60-61.

39. Le recensement de 1897 ne distingue pas les sunnites et les chiites. En revanche, les statistiques publiées à Tiflis et à Elisavetpol' les dénombrent séparément au niveau de chaque village en ce qui concerne le gouvernement d'Elisavetpol'. Les chiites représentent 58,55 \% des musulmans du district d'Elisavetpol', 98 \% de la ville elle-même, $68,80 \%$ au Zangezur, 71,62 \% dans le district de Karjagin, 87,54 \% dans celui de Dževanšir, $91,82 \%$ dans celui de Šuša (pourcentages établis à partir de statistiques du Kavakzskij Kalendar' (K.K.) na 1915 god, Tiflis: izd. ot Kanceljarii Kavkazskogo Namestnika, 
1914, p. 226-233, en considérant comme sunnites ceux qui sont dénombrés en tant que musulmans kurdes et montagnards).

40. Sur le parti Mudafie, voir Bagirova, Političeskie partii, p. 188-191.

41. Kričinski, Dokumenty, p. 22-23.

42. Ibid., p. 19.

43. Sur la biographie d'Agaev, voir A. Holly Shissler, Between two Empires : Ahmet Ağaoğlu and the New Turkey (...Ahmet Ağaoğlu), Londres : I.B. Tauris, 2003. Ici, p. 117.

44. CGIA GR (Archives historiques centrales de Géorgie), f. 94, op. 1, d. 309, 1. 142, cité par Lerner, « K voprosu o dejatel'nosti... », p. 92.

45. Tomris Azeri, The Memoirs, p. 3-4.

46. Baykara, Azerbaycan istiklal, p. 132.

47. GARF, f. 102, OO, 1908, d. 296, 1. 27.

48. Ibid., p. 31.

49. A. Ter Minassian, "Particularités de la révolution russe de 1905 en Transcaucasie », in Fr.-X. Coquin, C. Gervais-Francelle, éds., 1905, la première révolution russe, P. : Publications de la Sorbonne - Institut d'études slaves, 1986, p. 321.

50. GARF, f. 102, OO, 1908, d. 296, 1. 31.

51. E. Aknouni, Les plaies du Caucase, Genève: Fédération révolutionnaire arménienne, 1905, p. 341. L'historien Richard G. Hovannisian gratifie Voroncov-Daškov de l'adoption d'un «code opérationnel de conciliation" (H. Hovannisian, Armenia on the Road to Independance, Berkeley - Los Angeles : University of California Press, 1969, p. 20-21).

52. D.I. Ismail-Zade décrit une politique du vice-roi attentive à certaines des revendications de chaque nationalité et menant de front concessions, réformes et répression: Graf I.I. Voroncov-Daškov. Namestnik kavkazskij, [Le comte I.I. VoroncovDaškov. Vice-roi du Caucase], M.: ZAO Centrpoligraf, 2005, p. 129-142, 155-158; I.I. Voroncov-Daškov-administrator, reformator [I.I. Voroncov-Daškov, adminsitrateur, réformateur], SPb. : Nestor-Istoria, 2008, p. 67-109.

53. GARF, f. 102 OO, 1908, d. 296, 1. 31-32.

54. Kričinski, Dokumenty, p. 19, 25, 26, 29, 31, 32, 35, 41.

55. Ibid., p. 24, 29, 31.

56. Mirza Bala, Millî Azerbaycan hareketi, p. 58-59; Baykara, Azerbaycan istiklal, p. 133.

57. Bagirova, Političeskie partii, p. 175-176.

58. Ce programme figure en annexe de l'exposé du capitaine Ergardt, GARF, f. 102, OO, 1908, d. 296, 1. 36-39 verso et dans un rapport conservé à Baku, GAPPOD AR (Archives nationales des partis politiques et des mouvements sociaux de la république d'Azerbaïdjan), f. 276, op. 8, d. 217, 1. 49-58, reproduit dans Azizov, Difai, p. 339-348. la numérotation des articles diffère dans les deux documents, le préambule étant numéroté comme le premier article dans le second.

59. Les « humb » sont des cellules de 7 à 10 membres " conscients » du parti dašnak, organisées selon un principe strict de clandestinité et chargées de mener par tous les moyens la propagande du parti dans le peuple (GARF, f. 102, 1909, d. 14, 1. 9 verso).

60. Agdam et Hodžaly sont deux villages musulmans du district de Šuša, peuplés respectivement de 930 et 134 habitants (PKEG na 1910 g, section III, p. 91, 99). Ces villages 
sont situés à environ $12 \mathrm{~km}$ l'un de l'autre. Hodžaly se trouve sur l'unique route qui relie Agdam à Šuša, par le défilé d'Askeran.

61. GARF, f. 102, OO, 1908, d. 296, 1. 28-29.

62. GARF, f. 102, OO, 1908, d. 296, 1. 161 verso, 162.

63. Note du 10 février 1907 de Voroncov-Daškov à Nicolas II, citée par D.I. Ismail-Zade, Graf I.I. Voroncov-Daškov. Namestnik kavkazskij, p. 264.

64. V.N. Hudadov, « Sovremennyj Azerbajdžan », Novyj Vostok, 3, 1923, p. 181. L'article est presque entièrement consacré aux rapports entre Arméniens et Turcs de Transcaucasie. L'auteur, membre de la Société scientifique panrusse d'orientalisme, collabore régulièrement à sa revue Novyj Vostok.

65. GARF, f. 102, OO, 1909, d. 14, 1. 5 verso.

66. Sur ces différents ethnonymes et leur usage, voir Edith Ybert-Chabrier, « La pétition des musulmans du Caucase en réponse à l'oukase du 18 février 1905 ", Cahiers du Monde russe, 48 (2-3), avril-septembre 2007, p. 250, 254 ; V.A. Šnirel'man, Vojny pamjati : mify, identičnost' $i$ politika [Les guerres de mémoire: mythes, identités et politique], M.: Akademkniga, 2003, p. 33-35.

67. Mirza Bala, Milli Azerbaycan hareketi, p. 61

68. Hudadov, « Sovremennyj Azerbajdžan », p. 180-182.

69. Sur ces processus, voir Eva-Maria Auch, Muslim - Untertan - Bürger. Identitätswandel in gesellschaftlichen Transformationsprogressen der muslimischen Ostprovinzen Südkaukasiens (Ende 18. - Anfang 20. Jh.). Ein Beitrag zur vergleichenden Nationalismusforschung, Wiesbaden: Reichert-Verlag, 2004, p. 304-396, 433-455.

70. Ali-Merdan Toptchibachy (Topčibašev) [1865-1934], juriste et avocat assermenté (pricjažnyj poverennyj), rédacteur en chef du journal en langue russe de Baku Kaspij (1897), joue un rôle éminent parmi les musulmans de Russie de 1905 à 1917. Président du Parlement et ministre des Affaires étrangères de la république d'Azerbaïdjan, proclamée en mai 1918, il dirige la délégation azerbaïdjanaise à la Conférence de la Paix. Arrivé à Paris en mai 1919, il y vit en exil après la soviétisation de son pays.

71. Les trois résolutions adoptées lors du III congrès figurent en russe dans A. Aršaruni et H. Gabidullin, Očerki panislamizma i pantjurkizma $v$ Rossii [Essai sur le panislamisme en Russie], M : izd. Bezbožnik, 1931, p. 121-122. Le compte-rendu de ce III Congrès a été édité à Kazan' et apparaît aussi dans des publications du programme de l'Union des Musulmans. 145000 exemplaires de ces brochures en turc sont parus en 1906 à Kazan' et à Saint-Pétersbourg (S.M. Ishakov, «Pervaja russkja revoljucija i Sojuz rossijskih musul'man» [La Première révolution russe et l'Union des musulmans russes], in Sevost'janov, éd., Političeskie partii $v$ rossijskih revoljuciah $v$ načale Xx veka [Les partis politiques dans les révolutions russes du début du $x x^{e}$ siècle], $M:$ Nauka, 2005, p. 238).

72. S.M. Ishakov présente ces deux tendances comme les composantes d'une idéologie propre aux musulmans de Russie qui aurait été leur forme d'autoconservation ethnique dans le contexte russe, Ibid., p. 225.

73. Pour une vision synthétique de ces débats de 1917, voir A. Bennigsen, C. LemercierQuelquejay, L'Islam en Union soviétique, P.: Payot, 1968, p. 86-89; Aydin Balaev, Azerbajdžanskoe nacional'noe dviženie $v$ 1917-1918 [Le mouvement national azerbaïdjanais en 1917-1918], Baku : Elm, 1998, p. 66-76. 
74. A. Le Chatelier, « Les missions évangéliques et anglo-saxonnes », La conquête du monde musulman, Revue du Monde musulman, XVI (10), nov. 1911, p. 8-9.

75. GARF, f. 102, OO 1908, d. 296, 1. 31-32.

76. Bagirova, Političeskie partii, p. 171-172.

77. Kričinski, Dokumenty, p. 9, 19-21, 29. La Société musulmane de bienfaisance est créée à Baku en 1905 ; Une société du même nom pour la ville d'Elisavetpol' est fondée en 1906 (Auch, Muslim - Untertan - Bürger, p. 666-667).

78. Kričinski, Dokumenty, p. 35. Gidajat, créée en 1906, présente à Baku, Elisavetpol' et Nuha (Šeki) [Auch, Muslim - Untertan - Bürger, p. 667].

79. Kričinski, Dokumenty, p. 40-41.

80. Ibid., p. 20.

81. Ibid., p. 8-9.

82. Levan Georgevič Džandieri, prince géorgien, chargé de missions spéciales auprès de la vice-royauté du Caucase. Il était responsable (načalnik) de la police de Suhumi lors des troubles révolutionnaires de Gourie et a été congédié à la fin de1908 ou au début de 1909, en raison du rôle qu'il a alors joué, favorable au nationalisme géorgien et auquel se seraient opposés les Abkhazes.

83. Kričinski, Dokumenty, p. 40-42.

84. Ibid., p. 21,32 .

85. Ces communautés rurales (sel'skie obščestva) ont été organisées dans le cadre de la réforme introduite en Transcaucasie à partir de 1864, trois ans après celle abolissant le servage dans la Russie centrale. Ainsi sont instituées, en 1870, 335 communautés rurales dans le gouvernement d'Elisavetpol', avec une assemblée du village (sel'skij shod) et un maire (staršina) élu pour trois ans (Mill'man, Političeskij stroj, p. 170-177).

86. Kričinski, Dokumenty, p. 35.

87. Ibid., p. 40.

88. Ibid., p. 8, 20, 26, 31-32, 35-36; GARF, f. 102, 1909, d. 14, 1. 19 verso.

89. K. Zalevskij, « Nacional'nye dviženija [Les mouvements nationaux] », in L. Martov, P. Maslov et A. Potresov, éds., Obščestvennoe dviženie $v$ Rossii [Le Mouvement social en Russie], 4 vol., SPb. : Tip. to-va obščestvennaja pol'za, 1909-1914, t. IV, 1911, II ${ }^{\mathrm{e}}$ partie, livre 7 b, p. 224.

90. GARF, f. 102, OO, 1909, d. 14, 1. 3 recto et verso.

91. Kričinski, Dokumenty, p. 32.

92. GARF, f. 102, OO, 1908, d. 296, 1. 31-32.

93. Ibid., p. 36 verso-39 verso.

94. Kričinski, Dokumenty, p. 35-36.

95. Ibid., p. 21.

96. Ibid., p. 28.

97. Parmi eux citons: V. Kriven'kij, « Difai », in Političeskie Partii Rossii. Konec xix-Pervaja tret' Xx veka. Enciklopedija [Les partis politiques de Russie. Fin xixe-premier tiers du $\mathrm{xx}^{\mathrm{e}}$ siècle], M.: ROSSPEN, 1996, p. 186 ; Osmanl devleti ile azerbaycan türk hanlıkları, p. 212 ; Kričinski, Dokumenty, p. 18 ; Tomris Azeri, The Memoirs, p. 6.

98. GARF, f. 102, OO, 1908, d. 296, 1. 28. 
99. Baykara, Azerbaycan istiklal, 1. 136.

100. Ahmedov, Azerbajdžanskie Tjurki, p. 279-281.

101. Ibid., p. 279-283 ; GARF, f. 102, O0, 1908, d. 296, 1. 28.

102. Kričinski, Dokumenty, p. 8 ; Baykara donne le nom de deux chefs de police, l'un de Gandja, l'autre de Terter et d'un juge au tribunal militaire de Šuša exécutés pour avoir aidé les Arméniens, Azerbaycan istiklal, p. 136.

103. Ahmedov, Azerbajdžanskie Tjurki, p. 283.

104. Ainsi en est-il d'un certain Iskander Gadži Gusejn, du district de Novobajazet (gouvernement de Erevan), Kričinski, Dokumenty, p. 26, 30 ; d'un certain Mešadi Kara du village de Namarly (district de Dževanšir), tué pour concussion et usure, Ibid., p. 8; du propriétaire terrien d'Agdam, Mamiš bek Safarlibekov, père du Safarli bek Safarlibekov, dont la dénonciation hostile a été précédemment mentionnée, et de deux habitants de Šuša, Ahmedov, Azerbajdžanskie Tjurki, p. 284-285.

105. Tomris Azeri, The Memoirs, p. 5 ; Baykara, Azerbaycan istiklal, p. 136.

106. Kričinski, Dokumenty, p. 42.

107. Ahmedov, Azerbajdžanskie Tjurki, p. 280-283, 292-293.

108. Kričinski, Dokumenty, p. 26.

109. Ibid., p. 32.

110. Note du 10 février 1907 de Voroncov-Daškov à Nicolas II, in D.I. Ismail-Zade, Voroncov-Daškov, Kavkazskij namestnik, p. 264.

111. Mirza Bala, Millî Azerbaycan hareketi, p. 58 ; Baykara, Azerbaycan istiklal, p. 133, 135.

112. GARF, f. 102 , OO, 1908, d. 296, 1. 32. Mirza Bala cite précisément ce passage du manifeste (Millî Azerbaycan hareketi p. 58-59). Swietochowski met en exergue les notions d'unité des peuples de Transcaucasie, de lutte conjointe des Musulmans, Géorgiens et Arméniens, qui entreraient dans la tactique du parti Difai (« National Consciousness and political orientations in Azerbaiijan... », p. 216).

113. Kričinski, Dokumenty, p. 8, 20.

114. Voir note 17.

115. Kričinski, Dokumenty, p. 11-12.

116. Ibid., p. 21.

117. Ibid., p. 36-37. Une telle commission se réunit en septembre 1906 à Elisavetpol'. Les arbitres de paix des districts de Šusa, Dževanšir et Elisavetpol' doivent y fixer les conditions de levée du « bagry » - qui représente $1 / 10$ de la récolte -, compte tenu de la situation générée par les heurts arméno-tatars (Tiflisskij Telegraf, Tiflis, $\mathrm{n}^{\circ} 38$, 1er octobre 1906).

118. Kričinski, Dokumenty, p. 20, 35 ; GARF, f. 102, 00, 1908, d. 296, 1. 29.

119. Bagirova, Političeskie partii, p. 31, 36, 171.

120. Swietochowski, "The Himmät Party. Socialism and the national question in Russian Azerbaijan. 1904-1920», Cahiers du Monde russe et soviétique, XIX (1-2), janv.-juin 1978, p. 119-142 ; Bagirova, Političeskie partii, p. 29-44.

121. Ibid., p. 36-39. Observant les parcours politiques des 48 députés musulmans à l'Assemblée constituante, L.G. Protasov constate que leur appartenance à des partis socialistes ou libéraux dépendait d'interactions avec certains segments du monde 
politique russe, plutôt que d'une adhésion totale à telle ou telle vision du monde, Ljudi Učreditel'nogo sobranija [Les hommes de l'Assemblée constituante], M.: ROSSPEN, 2008, p. 144-146.

122. Bagirova, Političeskie partii, p. 38-39.

123. GIA AR, f. 524, op. I, d. 20, 1. 3-7.

124. Ibid., p. 5-6.

125. Ibid., p. 5, 7 .

126. Bagirova, Političeskie partii, p. 185, qui évoque ces perquisitions à partir d'un autre dossier des archives historiques de Baku.

127. GARF, f. 102, OO, 1908, d. 388, 1. 4-9. Sur le rôle joué par les partis Dašnakcutjun et Difai dans la diffusion de la littérature jeune-turque en Transcaucasie voir G.Z. Aliev, « K voprosu o pomošči azerbajdžanskoj demokratii mladotureskomu dviženiju» [Sur la question de l'aide de la démocratie azerbaïdjanais au mouvement jeune-turc], Turkologičeskij sbornik 1973, M. : Nauka, 1975, p. 187-192.

128. M. şükrü Hanioğlu, Preparation for a Revolution: The Young Turks, 1902-1908, New York : Oxford University Press, 2001, p. 157-161.

129. Sur ce que peut-être un «notable» dans la Turquie voisine, voir Elise Massicard, "Entre l'intermédiaire et "l'homme d'honneur". Savoir-faire et dilemmes notabiliaires en Turquie », Politix, XVII (67), 2004, p. 101-127, en particulier, p. 101-104.

130. Kričinski, Dokumenty, p. 25 ; 35-36.

131. Abdul Kerimbek Mehmandarov (1854-1929), médecin militaire et civil, membre des sociétés de bienfaisance et d'encouragement à l'enseignement de Šuša où ses efforts aboutissent à l'ouverture, en 1912, de la première école « russo-azerbaïdjanaise » de filles de cette ville.

132. Karabek Karabekov (1874-1953), médecin de Baku, originaire de Šuša, membre du Gummet au début de la révolution de 1905, publiciste. Il vit de 1911 à 1914 en Turquie où il sert d'agent secret du gouvernement russe auprès de la direction jeune turque, d'après Ajdyn Balaev. Leader le plus en vue du parti clérical "Iittihad Islam» (1917-1918) défendant un "socialisme islamique ", il travaille dans des institutions médicales de Moscou ou d'Asie centrale jusqu'à son arrestation en 1937.

133. Mamed Hasan Gadžinski (1875-1931), ingénieur de Baku, membre du Gummet, puis du Musavat (à partir de 1911), ministre des Affaires étrangères de la république d'Azerbaïdjan. Après la soviétisation, il est le premier adjoint du président du Gosplan de la république fédérative de Transcaucasie. Il est exécuté dans une prison de Tbilissi.

134. Ahmed Agaev ou Ağaoğlu (1869-1939) qui, après s'être considéré comme persan pendant ses études à Paris, milite au Caucase (Baku, Karabah), le quitte en 1909 pour Istanbul et devient l'un des théoriciens du nationalisme turc. Il s'engage dans les mouvements jeune-turc puis kémaliste. Sur son séjour à Paris, voir François Georgeon, Des Ottomans aux Turcs: Naissance d'une nation, Istanbul : Isis, 1995, p. 41-54; Shissler, Ahmet Ağaoğlu, p. 80-102.

135. Bejbut Dževanširskij ou Dževanšir Behbud Aga Azad ogly (1886-1921), ingénieur principal dans des entreprises pétrolières de Baku, membre de la direction de la Société musulmane de bienfaisance. Il devient ministre des Affaires intérieures (juin-déc. 1918) de la république d'Azerbaïdjan. Après la soviétisation, il travaille à nouveau dans l'industrie pétrolière et est abattu lors d'un déplacement professionnel à Istanbul. 
136. Isabek Ašurbekov (1878-1938), issu d'une très riche famille de Baku, finance de nombreuses sociétés de bienfaisance et soutient l'édition de journaux, notamment d'Iršad d'Ahmed Agaev. D'abord membre d'organisations sociale-révolutionnaire "Ittifag » et sociale-démocrate " Gummet ", il appartient au comité central du Difai et, dans les années 1917-1918, rejoint le parti clérical « Iittihad Islam ». Chargé de missions spéciales au ministère de l'Enseignement public de la république d'Azerbaïdjan, il est responsable d'un département d'édition relevant du Commissariat du peuple à l'Éducation après 1920. Il est exécuté en 1938.

137. Bagirova, Političeskie partii, p. 172-173. Ismail Zijathanov (1867-1920), adjoint du procureur de Tiflis puis avocat, député du gouvernement d'Elisavetpol' à la Première Douma (1906), il signe l'appel de Vyborg. Chef de la milice de la ville de Gandja (1917), il commande des régiments engagés contre les dašnaks (mars 1918) et est en charge de questions militaires dans le gouvernement de la république d'Azerbaïdjan (oct.- déc. 1918). Il est envoyé en Iran à la tête de la délégation diplomatique (1919) et est liquidé l'année suivante.

138. Ahund-Molla-Muhamed Pišnamaz-Zade (v. 1853-1937), issu d'une éminente famille cléricale chiite d'Elisavetpol', a parachevé sa formation spirituelle à Téhéran et à Nadjaf (Iraq, alors dans l'Empire ottoman). Cadi d'Elisavetpol' en 1895, il promeut l'enseignement religieux « moderne ». Attaqué par les traditionnalistes, il est suspendu de ses fonctions et détenu un an et demi. Libéré, il fonde à Elisavetpol', en 1906, une medrese dispensant un enseignement moderne aux futurs mollahs. Nommé en 1909 adjoint du cheikh-ul-islam, il lui succède en 1915.

139. Baykara, Azerbaycan istiklal, p.136-137; Tomris Azeri, The Memoirs, p. 2, 10-12. Alekperbek Kerbalai Gasan ogly Rafibekov (Rafibeyli) [1839-1919], a servi dans la police (1870-1896) puis a été durant 22 ans membre de la douma urbaine d'Elisavetpol'.

140. Bagirova, Političeskie partii, p. 172.

141. Alekperbek Rafibekov (Rafibeyli) a suivi un programme d'enseignement russe "malgré l'opposition des hommes de religion et le fanatisme ambiant », précise Mirza Bala, Millî Azerbaycan hareketi, p. 136. C'est aussi le cas d'Ahmed Agaev (Ağaoğlu), voir Shissler qui raconte avec des détails suggestifs sa scolarité (...Ahmet Ağaoğlu, p. 46-57)

142. Ibid., p. 52-56.

143. Asker-aga Adigezalov (1857-1910), du village de Gerai dans le gouvernement de Gandja, d'où son nom de plume de Gerani, a étudié à l'Académie agronomique PetrovskoRazumovskij de Moscou. Il y organise avec d'autres étudiants caucasiens la société " démocratique révolutionnaire Imdadie [Entraide]», destinée, semble-t-il, à aider les étudiants musulmans pauvres. Il collabore au premier journal en langue azérie, Ekinči [Le Laboureur] (1875) de Gasan bek Zardabi.

144. D.B. Seidzade, Iz istorii azerbajdžanskoj buržuazii v načale XX veka [De l'histoire de la bourgeoisie azerbaïdjanaise au début du $\mathrm{xx}^{\mathrm{e}}$ siècle], Baku: Elm, 1978, p. 52, 71-72; Bagirova, Političeskie partii, p. 164-167.

145. Ibid., p. 170. Pour la résolution d'août 1906, voir note 71.

146. Edith Ybert-Chabrier, "La pétition des musulmans du Caucase... », p. 243-258, en part. p. 254. Sur la campagne de pétitions par des musulmans des diverses régions et villes de l'Empire, voir S.M. Ishakov, Pervaja Russkaja Revoljucija i musul'mane Rossijskoj Imperii [La Première révolution russe et les musulmans de l'Empire russe], M.: izd. « Social' no-političeskaja Mysl' », 2007, p. 102-105, 113-125, 134-138. 
147. A.D. Seidzade, Iz istorii azerbajdžanskoj buržuazii, p. 73-74.

148. "Zapiska namestniku o posobii golodajuščim musul'manam i uregulirovanii kočevnogo dela [Note au vice-roi pour une subvention aux musulmans victimes de la famine et pour une réglementation de la vie nomade]», Archives de Toptchibachy, EHESS, valise 5, 1907, $\mathrm{n}^{\circ} 38$.

149. Shissler, Ahmet Ağaoğlu, p. 128.

150. Kričinski, Dokumenty, p. 20, 30.

151. Ibid., p. 39.

152. Ibid., p. 43.

153. Bagirova, Političeskie partii, p. 186.

154. Shissler, Ahmet Ağaoğlu, p. 132, 157.

155. « Sredi musul'man », Zakavkaz'e, Tiflis, n 120, 3 juillet 1909.

156. Sur l'ensemble de ces mesures répressives, voir Kričinski, Dokumenty, p. 44-47; Bagirova, Političeskie partii, p. 186-187.

157. KK na 1910 g., Tiflis, 1909, Adres-Kalendar', col. 377, 378, 386; K.K. na 1915 g., AdresKalendar', col. 164, col. 610. Bagirova précise que Mešadi Ali Rafief était le caissier du parti et Gamidbek Usubbekov était en charge de son secrétariat (Političeskie partii, p. 172). Mešadi Ali Rafief présidait encore en 1910 la $2^{\mathrm{e}}$ société de crédit mutuel d'Elisavetpol'. Des quatre conseillers de la douma urbaine, seul Gamidbek Usubbekov, dessinateurcartographe de l'administration municipale, n'occupe plus son poste en 1915.

158. K.K. na 1910 g., Adres-Kalendar', col. 413.

159. C'est le cas pour Alekperbek Rafibekov chez qui une perquisition est menée en novembre 1911 (GARF, f. 102, O0,13, 1912, 74 č-92-lb, 1.55 verso-56) ou pour Ahund-MollaMuhamed Pišnamaz-Zade, chez lequel sont trouvées, en 1912 à Nuha, des brochures qui montreraient la volonté de reprendre l'action du Difai (Azizov, Difai, p. 311-312).

160. Le télégramme de janvier 1909 du colonel Klementov, gouverneur général à titre provisoire du gouvernement d'Elisavetpol', le dit explicitement (Ibid., p. 309-310).

161. Sur les directions spirituelles sunnite et chiite de Transcaucasie instituées à Tiflis en 1872, voir A.J. Arapov, Islam $v$ rossijskoj imperii [L'Islam dans l'Empire russe], M.: Akademkniga, 2001, p. 210-247; sur l'opposition populaire aux clercs nommés par ces administrations: Firouzeh Mostashari, "Colonial Dilemnas: Russian Policies in the Muslim Caucasus ", in Robert G. Geraci, Michael Khodarkovsky, éds., of Religion and Empires: Missions, conversion and Tolerance in Tsarist Russia, Ithaca - London: Cornell University Press, 2001, p. 242-249.

162. GARF, f. 102, OO, 1908, d. 296, 1. 38-39 verso.

163. A. Altstadt-Mirhadi, «The forgotten factor: the shi'i mullahs of pre-revolutionary Baku ", in Ch. Lemercier-Quelquejay, G. Veinstein, S.E. Wimbush, éds., Passé turco-tatar, Présent soviétique, Louvain - P.: Peeters, Éditions de l'EHESS, 1986, p. 345-365; F. Georgeon, « Note sur le modernisme en Azerbaïdjan au tournant du siècle ", Cahiers du Monde russe, XXXVII (1-2), janvier-juin 1996, p. 97-106 ; Altay Göyüshov, «L'élan brisé : les intellectuels azéris et l'enseignement islamique avant la soviétisation », in B. Balci, R. Motika, éds., Religion et politique dans le Caucase postsoviétique, P. : Maisonneuve \& Larose, 2007, p. 121-131. 
164. L'analyse du style de vie javânmard porte sur l'Iran contemporain dans le contexte de la mondialisation (voir Fariba Adelkah, Être moderne en Iran, P.: Karthala, 1998, p. 13-17, 56, 103-105). Mais elle peut se transposer à la société chiite de Transcaucasie du début du xxe siècle, entraînée dans un processus d'industrialisation, de modernisation et de rationalisation qui l'amène à donner de nouvelles formes à des idéaux et comportements traditionnels.

165. Ces effectifs sont donnés par Bagirova, Političeskie partii, p. 171-172. Le rapport du 3 février 1907 de l'ambassade ottomane à Tiflis fait état de 20000 miliciens, chiffre extravagant (Osmanli devleti ile azerbaycan türk, p. 213-214).

166. Pavel Šehtman, Plamja davnyh požarov [La flamme des anciens incendies], paru dans la revue Pro Armenia, M., 1992-1993 et mis en ligne (http://www.armenianhouse.org/ shekhtman/docs-ru), en particulier la carte des heurts interethniques ; Ragim Gusejnov, Očerki revoljucionnogo dviženija v Azerbajdžane, vyp. 1. Revoljucija 1905-1907 [Le mouvement révolutionnaire en Azerbaïdjan. Partie I, La révolution de 1905-1907], Baku: Bakinskij Rabočij, 1926, p. 77-80. Pour des exposés synthétiques, établis à partir d'archives du GARF, du RGIA et du GIA AR, voir: A.S. Gatagova, «Mežetničeskie otnošenija [les rapports interethniques]", in A.N. Jakovlev éd., Rossija v načale XX veka [La Russie au début du $\mathrm{xx}^{\mathrm{e}}$ siècle], M.: Novyj Hronograf, 2002, p.155-156; J. Baberowski, "Civilizatorskja missija i nacionalizm v Zakavkaz'e : 1828-1914 gg [Mission civilisatrice et nationalisme en Transcaucasie]», in Novaja imperskaja istorija postsovetskogo prostranstva [Nouvelle histoire impériale de l'espace postsoviétique], Kazan' : Biblioteka žurnala « $A b$ Imperio ", 2004, p. 347-349.

167. Note du 10 février 1907 de Voroncov-Daškov à Nicolas II dans D.I. Ismail-Zade, Graf I.I. Voroncov-Daškov, Kavakzskij namestnik, p. 302.

168. Il s'agit de Louis Bonaparte (1864-1932), petit fils de Jérôme.

169. «Musul'manskoe dviženie v Elisavetpol'skoj gubernii [Le mouvement musulman dans le gouvernement d'Elisavetpol'] », Baku, Baku, n 117, 10 septembre 1905, p. 3.

170. Ismail-Zade, Graf I.I. Voroncov-Daškov, Kavkazskij namestnik, p. 132-134. Les débats de ce " congrès arméno-musulman ", sont diffusés dans la presse, par ex. dans Kaspij de Baku (n 39 à 56, du 23 février au 10 mars 1906).

171. V.N. Hudadov, « Sovremennij Azerbajdžan », p. 180-181.

172. E. Aknouni, Political Persecution: Armenian prisoners of the Caucasus (a page of the Tzar's persecution), New York, 1911, p. 30.

173. Swietochowski, Russia and Azerbaijan, p. 40 (à partir d'estimations données par R.H. Hovannissian, Armenia of the Road to Independance, p. 264).

174. Les rapports annuels du gouvernement d'Elisavetpol' consacrent une rubrique et un tableau aux «morts violentes et accidentelles». En comparant les données des années 1904-1907, on constate que le chiffre des victimes masculines de meurtre en 1905 dépasse de 2600 ceux des années 1904 et 1907 - pour 1906, le dépassement est de 500 -, et que le chiffre des victimes féminines de meurtre dépasse en 1905 de 300 ceux des années 1904, 1906 et 1907. Le commentaire du tableau de 1905 mentionne les heurts entre Arméniens et musulmans comme cause de la très grande augmentation du nombre des meurtres et précise que bien des assassinats, pillages et incendies ne sont ni déclarés par la population ni enregistrés (Priloženie ko vsepoddanejšemu otčetu o sostajanii Elisavetpol'skoj Gubernii [PVOSEG] za $1904 \mathrm{~g}$ [Annexe au rapport sur la situation du gouvernement d'Elisavetpol' en 1904], Elisavetpol': Tip.-skoropečatnaja H.A. Saakjanca, 1905, p.11; 
PVOSEG za 1905 g, Elisavetpol', 1906, p. 52, 53 et Vedomost' 11; Obzor Elisavetpol'skoj gubernii za 1906 god [Panorama du gouvernement d'Elisavetpol'], Tiflis, 1909, Vedomost'11; PVOSEG za 1907g, Elisavetpol', 1908, Vedomost'11.

175. GARF, f. 102 OO, 1908, d. 296, 1. 158 verso, 160 verso-161.

176. « Položenija, vyskazannyja armjanskim i musul'manskim delegatami v zacedanijah soveščanija o merah k prekraščeniju armjano-tatarskoj raspri [Positions exprimées par les délégués arméniens et musulmans lors des séances de la conférence sur les mesures pour faire cesser les massacres arméno-tatars]», Archives de Toptchibachy, EHESS, valise 9, p. 2.

177. M. Šahtahtinskij, « Armjano-tatarskija stolknovenija [les heurts arméno-tatars]», Kavkazskie Vesti, Tiflis, n 8, 31 mai 1906,p. 1; «Armjano-tatarskija otnošenija [Les relations arméno-tatares]», Kavkazskie Vesti, n 9, 10 juin 1906, p.1. Mohammed Sultanovič Šahtahtinskij (1846-1931), linguiste et publiciste, conseille aux musulmans de Russie de rallier le parti octobriste, qui défend le respect du manifeste du 17 octobre et soutient l'action du gouvernement («Pis'ma k musul'manam [Lettres aux musulmans] », Rossija, SPb., n 564, 25 septembre 1907, p. 1).

178. Ismail-Zade, «Iz istorii kočevogo hozajstva Azerbajdžana [Histoire de l'économie nomade de l'Azerbaïdjan]», Istoričeskie zapiski, 66, 1960, p. 96-136. Sur la description de cette économie pastorale et sur des préconisations pour en améliorer les conditions, V. D. Kallestinov, «Kočevoe skotovodstvo [l'élevage nomade]», Izvestija Obščestva obsledovanija i issledovanija Azerbajdžana, n³, Baku, 1926, p. 74-94; Terekeme, « Ob uslovijah žizni kočevnikov-skotovodov v Azerbajdžane [Les conditions de vie des éleveurs-nomades de l'Azerbaïdjan] », Ibid., p. 95-98.

179. Ismail-Zade, «Iz istorii kočevogo hozajstva Azerbajdžana », hors-textes entre les p. 108 et 109.

180. "Armjano-musul'manskij s"ezd [Le congrès arméno-musulman]», Sovremennik, Tiflis, 5(18) mars 1906, p. 2 (intervention d'Agaev dans les débats sur le désarmement des partis) ; Hudadov, « Sovremennyj Azerbajdžan », p. 180-181.

181. PKEG na 1910 g., otdel V, p. 26 verso-27 verso.

182. « Musul'manskoe dviženie v Elisavetpol'skoj gubernii »; J. Baberowski mentionne par ailleurs des attaques de villages arméniens par des Kurdes et des nomades Sahsevan («Civilizatorskaja missija i nacionalizm v Zakavkz’e », p. 349).

183. «Zapiska namestniku o posobii golodajuščim musul'manam... ». En février 1907, un appel signé du magnat du pétrole Tagiev, en qualité de président du comité central de collecte d'aides aux victimes de la famine du gouvernement d'Elisavetpol', paraît au même moment dans Kaspij. Il réclame la sécurisation des routes empruntées par les nomades («K pomošči golodajuščim [L'aide aux victimes de la famine] »), Kaspij, Baku, $\mathrm{n}^{\circ}$ 31, 8 février 1907).

184. G.J. Libarian, "Revolution and Liberation in the 1892 and 1907 programs of the Dashnaksutiun ", in Suny, éd., Transcaucasia : nationalism and social change, p. 187-198; Entin, éd., Političeskie partii, p. 401-404 ; N.B. Kirakosjan, "Sozdanie i dejatel'nost' partii "Dašnakcutjun" (1890-1907) [La création et l'activité du parti "Dašnakcutjun" (1890-1907] », in Istorija nacionalnyh političeskih partij Rossii [Histoire des partis politiques nationaux de Russie]), M. : ROSSPEN, 1997, p. 169-180. 
185. Anahide Ter-Minassian, «Le mouvement révolutionnaire arménien: 1890-1903», Cahiers du Monde russe et soviétique, XIV (4), 1973, p.551-553; Entin, éd., Političeskie partii, p. 412-413.

186. Fedor Fedorovič Timoškin (1872-?), d'origine paysanne, il est l'un des organisateurs, en mai 1905, de la Société patriotique de Tiflis, dont il devient le vice-président. Élu député de la population russe de Transcaucasie à la III ${ }^{e}$ Douma, membre de la fraction de droite, il appartient de 1909 à 1911 au Conseil de l'Union du peuple russe. Son destin à partir de 1917 reste inconnu.

187. SOGD 3 soz., Sessija II, Č. II, zasedanie 42, 28 janvier 1909, col. 520.

188. Bagirova, Političeskie partii, p. 50-53;84-87.

189. GARF, f. 102 OO, 1908, d. 296, p. 157, 160, 163-163 verso.

190. Vladimir Bobrovnikov, "Bandits and the State: Designing a "Traditional" Culture of Violence in the Russian Caucasus ", in Burbank, von Hagen, Remnev, éds., Russian Empire: Space, People, Power, 1700-1930, Michigan: Indiana University Press, 2007, p. 239-267.

191. Sur les kačak en Azerbaïdjan, voir Guseynov, Očerki revoljucionnogo dviženija, p. 37-46; Igrar Aliev, éd., Istorija Azerbajdžana s drevnejših vremen do načala XX veka [Histoire de l'Azerbaïdjan depuis les temps anciens jusqu'au début du $\mathrm{xx}^{\mathrm{e}}$ siècle], Baku: Elm 1995, p. 164. Guseynov tient les renseignements qu'il donne sur les vies de différents kačak de récits d'habitants des villages dont ils sont originaires.

192. Bobrovnikov, Musul'mane Severnogo Kavkaza: Obyčaj, Pravo, Nasilie: Očerki po istorii $i$ etnografii prava Nagornogo Dagestana [Les musulmans du Caucase du Nord: Coutume, droit, violence, essai d'histoire et d'ethnographie du droit du Haut-Daghestan], M.: Vostočnaja Literatura, 2002, p. 84.

193. Tifliskij Listok, Tiflis, 25.8.1905, cité par Pavel Šehtman, Plamja davnyh požarov, Rubrique Šuša; Peterburgskie Vedomosti, SPb., n 205, 26 août (8 septembre) 1905, p. 5 ; $n^{\circ} 208,30$ août (12 septembre) 1905, p. 1.

194. Tomris Azeri, The Memoirs, p. 2-3.

195. Baykara, Azerbaycan istiklal, p. 135.

196. V. Kozačkovskij, Razboi na Kavkaze [Les brigandages au Caucase], Vladikavkaz, 1913, p. 7, 59-65. Les nouveaux responsables de la police locaux, rompant avec la politique de leurs homologues en fonction en 1905-1906, poursuivent Zaid et déportent ses proches.

197. Bobrovnikov, in V.O. Bobrovnikov et I.L. Babič, éd., Severnyj Kavkaz v sostave Rossijskoj Imperii [Le Caucase du Nord au sein de l'Empire russe], M.: Novoe Literaturnoe Obozrenie, 2007, p. 292-293 ; Bobrovnikov, Musul'mane Severnogo Kavkaza, p. 84.

198. Guseynov, Očerki revoljucionnogo dviženija, p. 38, 41-42.

199. A. Mil'man, Političeskij stroj Azerbajdžana v xix-nač. xx vekov, p. 250-251.

200. Bruce Grant, The Captive and the Gift, Ithaca - Londres: Cornell University Press, 2009, p. xv, xvi.

201. GARF, f. 102, OO, 1908, d. 296, 1. 197 verso.

202. James H. Meyer, «Immigration, Return, and the Politics of Citizenship : Russian Muslims in the Ottoman Empire, 1860-1914 », International Journal of Middle East Studies, 39, 2007, p. 15-32. 
203. Richard Tapper, Frontier Nomads of Iran : A Political and Social History of the Shahsevan, Cambridge : Cambridge University Press, 1997, p. 248-250.

204. Ibid., p. 242-247. L'auteur décrit les pratiques de banditisme et mentionne le vol de milliers de moutons au Karabah; "Pod gnetom Šahsevanov" [Sous le joug des Šahsevan], Zakavkaz'e, Tiflis, n² 230, 17 novembre 1909, p. 3.

205. Voir par ex. M. Šahtahtinskij, "Osnovnaja pričina armjano-tatarskoj raspri [La raison principale du massacre arméno-tatar] », Kavakazskie Vesti, Tiflis, n 9, 1 juin 1906, pour le spectre de l'instauration d'un pouvoir arménien ; voir les déclarations de l'un des participants au congrès du Dašnakcutjun de novembre 1905, sur la restauration d'un khanat musulman et la menace du panislamisme, GARF, f. 102, O0, 1908, d. 296, 1. 158-160.

206. GARF, f. 102, 00, 1911, d. 74, č 6, Lit. b, l. 15, 17, 17 verso.

207. C'est ce qu'affirme sur les musulmans de Baku un rapport de décembre 1911, mentionnant l'abattement dans toutes les couches sociales et la multiplication des demandes d'obtention de la citoyenneté turque ou persane, adressées par des marchands aux consulats de l'Empire ottoman et de l'Iran (Ibid., p. 27).

208. S.V. Tjutjukin, «Roždenie rossijskoj mnogopartijnosti [La naissance du multipartisme russe]», in Sevost'janov, éd., Političeskie partii $v$ rossijskih revoljuciah, p. 112-130.

209. Buldakov, Krasnaja smuta: Priroda i posledstvija revoljucionnogo nasilija [Les troubles rouges : Nature et conséquences de la violence révolutionnaire], M. : ROSSPEN, $2^{\mathrm{e}}$ éd., 2010, p. 79-87 ; Beryl Williams, « 1905 : the view from the provinces », in J.D. Smele, A. Heywood, éds., The Russian Revolution of 1905. Centenary perspectives, Londres - New York : Routledge, 2005, p. 33-54.

210. J.A. Petrov, « 1905 : prolog graždanskoj vojny [Prologue à la guerre civile] », in A.N. Jakovlev, éd., Rossija v načale xx veka, p. 334-395.

211. V.P. Buldakov, « Krizis imperii i revoljucionnyj nacionalizm načala Xx v. v Rossii [La Crise de l'Empire et le nationalisme révolutionnaire du début $d u x^{e}$ siècle en Russie] ", Voprosy Istorii, 1, 2000, p. 29-45.

212. Martov, Maslov, Potresov, éds., Ob̌̌čestvennoe dviženie v Rossii.

213. Zalevskij, « Nacional'nye dviženija », p. 149-243.

214. Ibid., p. 222-223, 229-230.

215. Ibid., p. 232-237.

216. Ishakov, Pervaja russkaja revoljucija i musul'mane Rossijskoj imperii, passim. Sur le Difai, p. 251-252.

217. L'interpellation du Caucase a été discutée aux cours des séances 26 ( 3 décembre 1908), 30 (10 décembre), 37 (21 janvier 1909), 42 (28 janvier), 46 (4 février), 47 (5 février), dont les comptes-rendus sont publiés dans SOGD 3soz., Sessija II, Č.I, SPb. : Gos. Tip., 1908, col. 2207-2232, 2525-2576; Č. II., col. 69-138 ; 497-562, 867-976,1062-1172. Ces textes sont reproduits dans Ismail-Zade : I.I. Voroncov-Daškov-administrator, reformator, p. 112-320.

218. SOGD 3soz., Sessija II, Č. II col. 525-529, 534-538.

219. Gatagova, "Mežetničeskie otnošenija », p. 139, 147-151; D.A. Amanžolova, «Iz istorii mežetničeskih konfliktov v Rossii (1905-1916 gg.) [L'Histoire des conflits interethniques en Russie (1905-1916)] », Meždunarodnyj istoričeskij žurnal, nº 20 (I-8, I-12), 
2002 ,

http://history.machaon.ru/all/number_20/pervajmo/amansholova/part1/ idex.html.

220. SOGD 3soz., Sessija II, Č. II, col. 532-533.

221. M.G. Smith, "Anatomy of a Rumour: Murder Scandal, the Musavat Party and Narratives of the Russian Revolution in Baku, 1917-1920", Journal of Contemporary History, 36 (2), avril 2001, p. 216-217.

222. Sur la construction d'histoires nationales mythifiées en Arménie, en Azerbaïdjan et en Géorgie voir Šnirel'man, Vojny pamjati, en particulier pour l'Azerbaïdjan et le HautKarabah, p. 101-118, 194-237; sur ce même sujet étudié à partir des livres scolaires d'Azerbaïdjan, voir Sergej Rumjancev, "Geroičeskij epos i konstruirovanie obraza istoričeskogo vraga [l'Épopée héroïque et la construction de l'image de l'ennemi historique] », Ab Imperio, 2, 2005, p. 441-468.

223. Bagirova, Političeskie partii, p. 313-314.

224. "Rezoljucii prinjatye na Pervom Kavkazskom Kraevom s"ezde Musul'man zasedavšem ot 15-20 aprelja $1917 \mathrm{~g}$. [Résolutions prises au Premier Congrès régional des musulmans du Caucase, 15-20 avril 1917] », Archives de Toptchybachi, EHESS, valise 14.

225. «Postanovlenija Pervago Obšče-kavkazskago Musul'manskago s"ezda po organizacii sil Kavkazskih Musul'man [Résolutions du Premier congrès musulman caucasien sur l'organisation des forces des musulmans du Caucase] »; «O reorganizacii duhovnyh učreždenij [La réorganisation des institutions spirituelles] », 20 avril 1917, Archives de Toptchybachi, EHESS, valise 14; Balaev, Azerbajdžanskoe nacional'noe dviženie, p. 64-71.

226. Azizov mentionne la participation du Difai au Comité exécutif formé à Gandja et sa constitution d'unités militaires, d'après $\mathrm{N}$. şeyxzamanl, ainsi que sa présence à une convention des partis politiques azerbaïdjanais de cette ville décrite dans le journal Ačyg Sez du 13 octobre 1917, d'après Mirza Bala, Difai, p. 313-314.

227. Bagirova, Političeskie partii, p. 315; Balaev, Azerbajdžanskoe nacional'noe dviženie, p. 62-64.

228. Ibid., p. 83.

229. Nasib bek Usubbekov (1881-1920), ancien collaborateur du Terdjuman de Gasprinskij qui émigre en Turquie en 1908 puis s'établit à Gandja, où il est l'un des membres de la douma urbaine et l'un des fondateurs du « Parti turc des fédéralistes en Russie» en avril 1917. Il devient président du Conseil des ministres (1919-1920) de la république d'Azerbaïdjan, assassiné en mai 1920. Il est le frère de Gamidbek Usubbekov (voir note 157).

230. Hudadat Rafibekov (1878-1920), médecin, directeur de clinique à Elisavetpol' et membre de la douma urbaine de cette ville (au moins de 1910 à 1915), il devient ministre de la Santé publique (1918) de la république d'Azerbaïdjan puis gouverneur général du gouvernement de Gandja. Arrêté pendant l'insurrection antisoviétique de Gandja, il est fusillé. Il est le fils d'Alekper bey Rafibekov.

231. «Rezoljucii prinjatye na Pervom Kavkazskom Kraevom s"sezde... ».

232. "Musul'manskij s"ezd [Le congrès musulman] », Kaspij, nº 89,23 avril (6 mai) 1917, p. 4. 
233. T. Swietochowski, Russian Azerbaijan 1905-1920 : The Shaping of National Identity in a Muslim Community, Londres - New York - Melbourne: Cambridge University Press, 1985 , p. 33, 59.

234. En plus des nombreux travaux cités dans les notes de cet article, il faut signaler R.A. Vekilov, Istorija vozniknovenija Azerbajdžanskoj respubliki [Histoire de la naissance de la république d'Azerbaïdjan], Baku: Elm, 1998; Michael A. Reynolds, «Buffers, not Brethren: Young Turk Military Policy in the First World War and the Myth of Panturanism », Past and Present, 203 (1), mai 2009, p. 137-179, en particulier pour l'analyse des relations entre les Ottomans, les Azerbaidjanais et les Arméniens en 1918.

\section{RÉSUMÉS}

Résumé

Seule organisation politique des musulmans du sud du Caucase jouissant d'une certaine assise populaire, le Difai est actif de 1906 à 1908. Il adopte des modes d'actions déjà éprouvés sur le terrain caucasien par le parti arménien Dašnakcutjun : recours au terrorisme ciblé, levée de milices armées. Se définissant comme une organisation panmusulmane du Caucase et de Crimée, il défend des enjeux locaux : peuplement musulman du Karabah, accès des pâturages d'été de cette région aux transhumants. Parti révolutionnaire selon les analyses de la police, le Difai constitue en fait un groupement de notables promouvant un programme réformiste musulman, acquérant de l'influence au sein de la population et contribuant au développement de sa conscience nationale. En pénétrant dans la vie locale du gouvernement d'Elisavetpol' (Gandja) grâce aux rapports policiers et à divers documents d'époque (journaux, annuaires officiels...), l'article tentera de contextualiser l'action politique et la violence, d'analyser les représentations qui ont durablement influencé l'historiographie et de mettre en exergue certains traits communs au Difai et aux mouvements sociopolitiques de l'Azerbaïdjan des années 1917-1920.

Abstract

The only political organization of Southern Caucasus Moslems to enjoy a popular base of support, the Difai was active between 1906 and 1908. It adopted the methods previously deployed in Caucasus territory by the Armenian Dashnaktsutiun party: recourse to targeted terrorism and recruitment of armed militia. Defining itself as a pan-Muslim organization of the Caucasus and Crimea, it took up local issues: Muslim settlement in Karabakh and transhumant access to summer pastures. Dubbed a revolutionary party by police analysis, the Difai was actually a grouping of leading citizens, promoting a Muslim reformist programme, gaining influence over the population and contributing to the development of its national consciousness. By gaining insight into the local life of the Elisavetpol' (Ganja) government, using police reports and various contemporary documents (newspapers, official yearbooks...), this article seeks to contextualize political action and violence, to analyze representations of enduring influence on the historiography, and to highlight some traits common to the Difai and the socio-political movements in Azerbaijan between 1917 and 1920. 
AUTEUR

ÉDITH YBERT-CHABRIER

Centre d'études turques, ottomanes, balkaniques et centrasiatiques, EHESS Centre d'études des mondes russe, caucasien et centre-européen, EHESS 